\title{
The Arabidopsis Cysteine-Rich Receptor-Like Kinase CRK36 Regulates Immunity through Interaction with the Cytoplasmic Kinase BIK1
}

\author{
Dong Sook Lee ${ }^{1}$, Young Cheon Kim ${ }^{1+}$, Sun Jae Kwon ${ }^{1+}$, Choong-Min Ryu ${ }^{2}$ and \\ Ohkmae K. Park ${ }^{1 *}$ \\ ${ }^{1}$ Department of Life Sciences, Korea University, Seoul, South Korea, ${ }^{2}$ Molecular Phytobacteriology Laboratory, KRIBB, \\ Daejeon, South Korea
}

\section{OPEN ACCESS}

Edited by:

Adi Avni,

Tel Aviv University, Israel

Reviewed by:

Hong-Gu Kang,

Texas State University, United States

Yangrong Cao,

Huazhong Agricultural University,

China

*Correspondence:

Ohkmae K. Park

omkim@korea.ac.kr

${ }^{\dagger}$ Present Address:

Young Cheon Kim,

Department of Bioresource

Engineering, Sejong University, Seoul,

South Korea

Sun Jae Kwon,

Accugene Co. Ltd., Incheon,

South Korea

Specialty section:

This article was submitted to

Plant Microbe Interactions,

a section of the journal

Frontiers in Plant Science

Received: 31 July 2017 Accepted: 11 October 2017 Published: 27 October 2017

Citation:

Lee DS, Kim YC, Kwon SJ, Ryu C-M and Park OK (2017) The Arabidopsis Cysteine-Rich Receptor-Like Kinase CRK36 Regulates Immunity through Interaction with the Cytoplasmic Kinase BIK1. Front. Plant Sci. 8:1856. doi: $10.3389 /$ fpls.2017.01856
Receptor-like kinases are important signaling components that regulate a variety of cellular processes. In this study, an Arabidopsis cDNA microarray analysis led to the identification of the cysteine-rich receptor-like kinase CRK36 responsive to the necrotrophic fungal pathogen, Alternaria brassicicola. To determine the function of CRK36 in plant immunity, T-DNA-insertion knockdown (crk36) and overexpressing (CRK36OE) plants were prepared. CRK36OE plants exhibited increased hypersensitive cell death and ROS burst in response to avirulent pathogens. Treatment with a typical pathogen-associated molecular pattern, flg22, markedly induced pattern-triggered immune responses, notably stomatal defense, in CRK36OE plants. The immune responses were weakened in crk36 plants. Protein-protein interaction assays revealed the in vivo association of CRK36, FLS2, and BIK1. CRK36 enhanced flg22-triggered BIK1 phosphorylation, which showed defects with Cys mutations in the DUF26 motifs of CRK36. Disruption of BIK1 and RbohD/RbohF genes further impaired CRK36-mediated stomatal defense. We propose that CRK36, together with BIK1 and NADPH oxidases, may form a positive activation loop that enhances ROS burst and leads to the promotion of stomatal immunity.

Keywords: Arabidopsis thaliana, pattern-triggered immunity, stomatal immunity, cysteine-rich receptor-like kinase, CRK36, BiK1, FLS2, NADPH oxidase

\section{INTRODUCTION}

Plants are exposed to a myriad of microbes during their lifespan and they have evolved two layers of immunity to defend against microbial pathogens. The first layer of immunity is referred to as pattern-triggered immunity (PTI), which is triggered upon recognition of pathogenassociated molecular patterns (PAMPs) by pattern recognition receptors (PRRs) (Macho and Zipfel, 2014; Zipfel, 2014). Activation of PRRs by PAMPs triggers PTI responses, including production of reactive oxygen species (ROS), ion fluxes, activation of mitogen activated protein kinases (MAPKs), expression of defense-related genes, callose deposition, and stomatal closure (Boller and Felix, 2009; Nicaise et al., 2009). One of the best characterized PRRs is the leucine-rich repeat (LRR) receptor-like kinase (RLK) flagellin-sensing 2 (FLS2), which recognizes flagellin or flagellin-derived peptide flg22 (Chinchilla et al., 2006; Robatzek et al., 2006). 
Upon ligand binding, FLS2 recruits another LRR-RLK brassinosteroid insensitive 1 (BRI1)-associated kinase 1 (BAK1), forming an active receptor complex (Chinchilla et al., 2007; Heese et al., 2007; Monaghan and Zipfel, 2012; Koller and Bent, 2014). This leads to phosphorylation and activation of the downstream receptor-like cytoplasmic kinases (RLCKs), Botrytis-induced kinase (BIK1), and other PBS1-like (PBL) proteins (Veronese et al., 2006; Lu et al., 2010; Zhang et al., 2010). Activated BIK1 dissociates from the receptors, and in turn, phosphorylates the NADPH oxidase RbohD, leading to ROS burst and stomatal immunity (Kadota et al., 2014; Li et al., 2014).

PTI can be overcome by pathogenic microbes that inject effectors into plant cells through the type III secretion system, resulting in effector-triggered susceptibility (ETS) (Shao et al., 2003; Zhang et al., 2007; Shan et al., 2008). As a result of coevolution, plants have developed a second layer of plant immunity, the so-called effector-triggered immunity (ETI), in which plant resistance $(\mathrm{R})$ proteins lead to the recognition of effectors and suppression of ETS (Mackey et al., 2002). ETI induces stronger and more prolonged immune responses than PTI and is frequently associated with programmed cell death (PCD), referred to as the hypersensitive response (HR), which restricts pathogen growth at the infection site (Coll et al., 2011). ETI and PTI activate common responses, including transcriptional reprogramming, ROS production, and MAPK activation, which suggests that they share downstream signaling components (Tsuda and Katagiri, 2010).

RLKs are conserved upstream signaling molecules that regulate a number of biological processes, including plant development and stress adaptation (Diévart and Clark, 2004; Osakabe et al., 2013). RLKs belong to one of the largest gene families with more than 600 members in Arabidopsis, and are classified into subfamilies according to the types of their extracellular domains (Shiu and Bleecker, 2001). Cysteine-rich receptor-like kinases (CRKs), also called domain of unknown function 26 (DUF26) RLKs, form a subfamily of RLKs with more than 40 members (Chen, 2001; Wrzaczek et al., 2010). Their extracellular domains contain 2 copies of a DUF26 motif having the sequence $\mathrm{C}-\mathrm{X} 8-\mathrm{C}-\mathrm{X} 2-\mathrm{C}$ with conserved Cys residues. CRKs play roles in disease resistance and cell death in plants (Chen et al., 2003; Acharya et al., 2007; Ederli et al., 2011). In gene expression analyses, CRKs were induced by treatments with $\mathrm{O}_{3}$, salicylic acid (SA), PAMPs, and pathogens (Du and Chen, 2000; Wrzaczek et al., 2010). Overexpression of CRK5 and CRK13 in Arabidopsis led to enhanced resistance to Pseudomonas syringae pv. tomato (Pst) DC3000 and HR-like cell death (Chen et al., 2003; Acharya et al., 2007). CRK4, CRK19, and CRK20 also activated rapid cell death in transgenic plants (Chen et al., 2004). CRK45 (also called ACRK1)-overexpressing plants showed enhanced resistance to Pst DC3000, whereas crk45 mutant plants were more susceptible to Pst DC3000, suggesting a positive role in disease resistance (Zhang et al., 2013). Increased expression of CRK28 enhanced resistance to Pst DC3000 in Arabidopsis and induced cell death in Nicotiana benthamiana (Yadeta et al., 2017). In contrast, CRK20 may regulate pathogenic defense in a negative way, as demonstrated by that its loss-of-function mutants increased resistance to Pst DC3000 (Ederli et al., 2011). Overexpression of CRK4, CRK6, and CRK36 enhanced PTI responses in Arabidopsis, resulting in increased resistance to Pst DC3000 (Yeh et al., 2015). Several CRKs have been shown to be implicated in abiotic stress responses (Bourdais et al., 2015; Ramegowda and Senthil-Kumar, 2015). Knockdown of CRK36 and knockout of CRK45 increased sensitivity to abscisic acid (ABA) and osmotic stress in Arabidopsis (Tanaka et al., 2012). In addition, crk5 mutant plants showed accelerated senescence and enhanced cell death phenotypes in response to UV radiation (Burdiak et al., 2015). It has been demonstrated that CRKs, including CRK5, CRK36, and CRK45, function in both biotic and abiotic stress responses.

In this study, CRK36 was identified as one of highly expressed genes in response to the necrotrophic fungal pathogen Alternaria brassicicola in Arabidopsis. CRK36 overexpression in Arabidopsis enhanced hypersensitive cell death, ROS production, and disease resistance to $P$. syringae. In addition, flg22triggered ROS burst and stomatal closure were increased in CRK36-overexpressing plants in a BIK1- and NADPH oxidasedependent manner. CRK36 directly interacted with and induced phosphorylation of BIK1 in response to flg22 treatment. These results suggest that $\mathrm{CRK} 36$, in association with BIK1, plays an essential role in plant innate immunity by regulating ROS production and signaling of NADPH oxidases.

\section{MATERIALS AND METHODS}

\section{Plant Materials}

Arabidopsis thaliana (ecotype Columbia, Col-0) plants were grown at $23^{\circ} \mathrm{C}$ under long-day conditions (16-h light/8-h dark cycle) for general growth and reproduction, and under shortday conditions (8-h light/16-h dark cycle) for pathogen infection. $N$. benthamiana plants were grown at $28^{\circ} \mathrm{C}$ under long-day conditions (16-h light/8-h dark cycle). The following mutant plants were used in this study: crk36-1 (SALK_035659), crk36-2 (SALK_100834), crk36-3 (SALK_116300), bik1 (Lu et al., 2010), and rbohD/F (Kwak et al., 2003). T-DNA insertion sites were verified by sequencing, and homozygous lines were selected. To generate CRK36OE plants, DNA fragments for CRK36 were amplified from an Arabidopsis cDNA library by PCR and cloned into the pBI121 binary vector (Clonetech) under the control of the cauliflower mosaic virus (CaMV) $35 \mathrm{~S}$ promoter. To generate pCRK36:GUS plants, the CRK36 promoter region ( -1 to $-1,365$ bp) was amplified from Arabidopsis gDNA by PCR and cloned into the pCAMBIA1303 vector containing a GUS gene. CRK36 mutants, CRK36K ${ }^{K 268 E}, C R K 36^{C 12345 A}$, and CRK36 ${ }^{C 6789 A}$, were generated by site-directed mutagenesis using the primers in Table S1. The mutated sequences were confirmed by sequencing. All constructs were transformed into Arabidopsis plants using the floral dip method (Clough and Bent, 1998). Transformants were selected on 1/2 MS medium containing $30 \mu \mathrm{g} / \mathrm{mL}$ kanamycin and homozygous T3 or T4 seeds were used for experiments.

\section{Plant Treatments}

For pathogen infection, 6-week-old plants grown under short-day conditions in an 8-h light/16-h dark cycle were used. 
Treatments with A. brassicicola, $P$. syringae, and E. carotovora were performed as previously described (Oh et al., 2005). For A. brassicicola infection, leaves were inoculated onto leaves by applying $10 \mu \mathrm{L}$ of water or spore suspension $\left(10^{6}\right.$ spores $\left./ \mathrm{mL}\right)$. For $P$. syringae infection, leaves were infiltrated with $10 \mu \mathrm{L}$ of $\mathrm{MgCl}_{2}(10 \mathrm{mM})$ or bacterial suspensions $\left(10^{6} \mathrm{cfu} / \mathrm{mL}\right)$. For E. carotovora infection, leaves were infiltrated with $10 \mu \mathrm{L}$ of $\mathrm{NaCl}(0.9 \%)$ or bacterial suspension $\left(10^{7} \mathrm{cfu} / \mathrm{mL}\right)$. For flg22 treatment, leaves were infiltrated with water or $1 \mu \mathrm{M}$ flg22 for $4 \mathrm{~h}$ (Kwon et al., 2013). For hormone treatments, 6-week-old plants grown under short-day conditions (8-h light/16-h dark cycle) were sprayed with water (mock), SA $(1 \mathrm{mM})$, ethephon (ET; $1.5 \mathrm{mM}$ ), and methyl jasmonate (MeJA; $50 \mu \mathrm{M})$ dissolved in water. The treated plants were maintained at $100 \%$ humidity for the indicated times.

\section{Gene Expression Analysis}

Gene expression was determined by quantitative real-time RTPCR using KAPA ${ }^{\mathrm{TM}}$ SYBR FAST qPCR master mix with genespecific primers (Table S1) on a LightCycler 480 system (Roche), according to the manufacturer's protocol. The expression levels of tested genes were standardized to the constitutive expression level of ELF1A and calculated using the $2^{-\Delta \Delta t}$ method (Schmittgen and Livak, 2008). Experiments were repeated at least 3 times with biologically independent samples.

\section{Microarray Analysis}

Leaves of 6-week-old plants were inoculated with $10 \mu \mathrm{L}$ water or suspension of $A$. brassicicola spores $\left(5 \times 10^{5}\right.$ spores $\left./ \mathrm{mL}\right)$ and incubated for $6 \mathrm{~h}$ as previously described (Oh et al., 2005). To analyze the transcript levels in plants treated with A. brassicicola, Affymetrix ATH1 microarray analysis was carried out. The expression levels were normalized by global scaling using GENPLEX software (Istech, Korea). Differentially expressed genes with at least two-fold changes are listed in Table S2.

\section{Histochemical Staining}

For GUS staining, $p C R K 36: G U S$ plants were stained in a solution containing the substrate 5-bromo-4-chloro-3-indolyl$\beta$-D-glucuronide (X-Gluc) at $37^{\circ} \mathrm{C}$ as previously described (Jefferson et al., 1987). Stained tissues were cleared by several washings of $70 \%$ ethanol and examined under a light microscope. $\mathrm{H}_{2} \mathrm{O}_{2}$ was detected by $3,3^{\prime}$-diaminobenzidine (DAB) staining as previously described (Torres et al., 2002). Leaves were placed in $1 \% \mathrm{DAB}$ solution (Sigma-Aldrich) overnight and destained with $70 \%$ ethanol. Images were captured using a microscope (Leica EZ4D), converted to greyscale, and then inverted to blackand-white images. The brightness of the inverted images was measured using ImageJ software (NIH) to quantify the intensity of brown color. Trypan blue staining was performed as previously described (Bowling et al., 1997). Leaves were immersed in lactic acid-phenol-trypan blue solution $(2.5 \mathrm{mg} / \mathrm{mL}$ trypan blue, $25 \%$ lactic acid, 23\% water-saturated phenol, 25\% glycerol) and boiled for $1 \mathrm{~min}$. Stained leaves were placed in a $60 \%$ chloral hydrate solution and finally equilibrated with 50\% glycerol. Callose deposition was visualized by aniline blue staining as previously described (Clay et al., 2009). Leaves were fixed in acetic acid:ethanol (1:3) and then stained with $5 \mathrm{mg} \mathrm{mL}^{-1}$ aniline blue for $1 \mathrm{~h}$. Stained leaves were observed under a confocal microscope (Zeiss Imager.A2).

\section{Apoplastic ROS Assay}

ROS was measured as previously described (Smith and Heese, 2014). Leaf discs $\left(0.5 \mathrm{~cm}^{2}\right)$ were incubated in $10 \mu \mathrm{L}$ of distilled water overnight in a 96-well plate. Water was then replaced by a reaction solution supplemented with $100 \mathrm{nM}$ of flg22. $\mathrm{H}_{2} \mathrm{O}_{2}$ levels were measured using the ROS-Glo ${ }^{\mathrm{TM}} \mathrm{H}_{2} \mathrm{O}_{2}$ Assay kit (Promega) in a luminometer (Luminoskan, Thermo LabSystems).

\section{Ion Leakage Assay}

Ion leakage experiments were performed as previously described (MacKey et al., 2003). Leaves were infiltrated with bacterial suspensions of Pst DC3000 (AvrRpm1) at $2 \times 10^{8} \mathrm{cfu} / \mathrm{mL}$. Leaf discs $\left(0.5 \mathrm{~cm}^{2}\right)$ were washed with $30 \mathrm{~mL}$ of distilled water for $30 \mathrm{~min}$ and then transferred into $10 \mathrm{~mL}$ distilled water. Ion conductivity was measured over time using a conductivity meter (Thermo Scientific).

\section{Stomatal Aperture Measurement}

Stomatal aperture was measured as previously described (Li et al., 2014). Leaf peels were collected from the abaxial side of 6-weekold plants and floated in a buffer (10 mM MES, pH 6.15, $10 \mathrm{mM}$ $\mathrm{KCl}$, and $10 \mu \mathrm{M} \mathrm{CaCl}_{2}$ ) for $2 \mathrm{~h}$ under light condition to ensure that most stomata were open prior to treatment. Stomatal images were captured using an optical microscope (Zeiss Imager.A2) and stomatal length and width were measured using ImageJ software (NIH).

\section{Yeast Two-Hybrid Analysis}

A yeast two-hybrid assay was performed with the GAL4 system (Clontech), according to the manufacturer's instructions. DNA regions corresponding to the kinase domains of CRK36, FLS2, CERK1, and BAK1, and the full-length of BIK1 were PCR-amplified with gene-specific primers (Table S1) and cloned into the pCR2.1-TOPO vector (Invitrogen). The constructs were subsequently transferred into the pGBKT7 and pGADT7 destination vectors, encoding the GAL4 DNA-binding domain $(\mathrm{BD})$ and activation domain $(\mathrm{AD})$, respectively. The resulting fusion constructs were transformed into the AH109 yeast strain. The transformants were grown on SD/-Leu-Trp medium, and then transferred to SD/-Ade-His-Leu-Trp medium. Transactivation activity was further evaluated based on the activity of $\alpha$-galactosidase on SD/-Ade-His-Leu-Trp medium containing $40 \mathrm{mg} / \mathrm{L}$ of $\mathrm{X}-\alpha-\mathrm{Gal}$.

\section{BiFC Assay}

To generate the BiFC constructs, BIK1 and CRK36 were PCR-amplified using gene-specific primers (Table S1). The PCR products were cloned into the pSPYNE-35S or pSPYCE$35 \mathrm{~S}$ vector for split YFP N-terminal or C-terminal fragment expression (Walter et al., 2004), fusing BIK1 to the N-terminal fragment of YFP (BIK1-YFP ${ }^{\mathrm{N}}$ ) and CRK36 to the C-terminal fragment of YFP (CRK36-YFPC). Agrobacterium tumefaciens $\mathrm{C} 58 \mathrm{C} 1$ harboring the $\mathrm{BiFC}$ constructs was coinfiltrated 
into $N$. benthamiana leaves. For expression in Arabidopsis protoplasts, PCR constructs for bZIP63, CRK36, FLS2, and $B I K 1$ were cloned into the pUC-SPYNE or pUC-SPYCE vector, generating the recombinant vectors pUC-SPYNE:bZIP63, pUC-SPYCE:bZIP63, pUC-SPYCE:CRK36, pUC-SPYNE:FLS2, and pUC-SPYNE:BIK1. The constructs were cotransfected into Arabidopsis mesophyll protoplasts by polyethylene glycol transfection (Yoo et al., 2007). The transfected leaves and protoplasts were visualized using a confocal microscope (LSM 510 META, Zeiss) with excitation at $488 \mathrm{~nm}$ and emission at $543 \mathrm{~nm}$.

\section{GST Pull-Down Assay}

A pull-down assay was performed as previously described (Huh et al., 2010), with some modifications. GST or GST-fused BIK1 $(10 \mu \mathrm{g})$ was incubated with His-tagged CRK36 $(10 \mu \mathrm{g})$ in a binding buffer $(20 \mathrm{mM}$ Tris- $\mathrm{HCl}, \mathrm{pH} 7.4,200 \mathrm{mM} \mathrm{NaCl}$, and $1 \mathrm{mM}$ EDTA) for $2 \mathrm{~h}$ at $4{ }^{\circ} \mathrm{C}$. Glutathione sepharose $4 \mathrm{~B}$ beads (GE healthcare) were added, incubated for $2 \mathrm{~h}$, and washed 3 times with a washing buffer $(20 \mathrm{mM}$ Tris- $\mathrm{HCl}, \mathrm{pH}$ 7.4, $200 \mathrm{mM}$ $\mathrm{NaCl}, 1 \mathrm{mM}$ EDTA, and $0.5 \%$ Triton X-100). Bound proteins were eluted by boiling in 2X Laemmli sample buffer $(100 \mathrm{mM}$ Tris- $\mathrm{HCl}, \mathrm{pH} 6.8,10 \%$ SDS, 30\% glycerol, $5 \% \beta$-mercaptoethanol, and $0.02 \%$ bromophenol blue), separated by SDS-PAGE, and visualized by immunoblotting using anti-GST and anti-His antibodies (Abcam).

\section{Co-immunoprecipitation Assay}

Co-immunoprecipitation experiments were performed as previously described (Huh et al., 2010) with some modifications. Proteins were extracted from $N$. benthamiana leaves using an extraction buffer [50 mM Tris- $\mathrm{HCl}, \mathrm{pH} 8.0,150 \mathrm{mM} \mathrm{NaCl}$, $1 \%$ Triton X-100, $0.5 \%(\mathrm{w} / \mathrm{v})$ sodium deoxycholate, $1 \mathrm{mM}$ PMSF, and $1 \mathrm{x}$ protease inhibitor cocktail (Roche)] with gentle shaking for $1 \mathrm{~h}$ at $4^{\circ} \mathrm{C}$. Lysates were centrifuged at 12,000 $\mathrm{rpm}$ for $10 \mathrm{~min}$ at $4^{\circ} \mathrm{C}$, and the supernatant was incubated with anti-Myc antibody (Abcam) overnight at $4^{\circ} \mathrm{C}$. Protein A sepharose beads (GE healthcare) were added and washed 3 times with an extraction buffer. Bound proteins were eluted by boiling in 2X Laemmli sample buffer $(100 \mathrm{mM}$ Tris- $\mathrm{HCl}, \mathrm{pH}$ $6.8,10 \%$ SDS, $30 \%$ glycerol, $5 \% \beta$-mercaptoethanol, and $0.02 \%$ bromophenol blue), separated by SDS-PAGE, and visualized by immunoblotting using anti-Myc and anti-HA antibodies (Abcam).

\section{BIK1 Phosphorylation Assay}

BIK1 phosphorylation was determined by a BIK1 mobility shift as previously described (Lu et al., 2010). Protoplasts were transfected with BIK1-HA construct and treated with $1 \mu \mathrm{M}$ flg22 for $15 \mathrm{~min}$. Total proteins were extracted using an extraction buffer [10 mM HEPES, pH 7.5, $100 \mathrm{mM} \mathrm{NaCl}, 1 \mathrm{mM}$ EDTA, $10 \%$ glycerol, $0.5 \%$ Triton $\mathrm{X}-100$, and $1 \mathrm{x}$ protease inhibitor cocktail (Roche)], and treated with calf intestine phosphatase (New England Biolabs) to trigger dephosphorylation. Extracted proteins were subjected to boiling in $2 \mathrm{X}$ Laemmli sample buffer (100 mM Tris- $\mathrm{HCl}, \mathrm{pH}$ 6.8, 10\% SDS, 30\% glycerol, 5\% $\beta$ mercaptoethanol, and $0.02 \%$ bromophenol blue), separated by
SDS-PAGE, and visualized by immunoblotting with anti-HA antibody (Abcam).

\section{RESULTS}

\section{Identification of CRK36 as an \\ A. brassicicola-Responsive Gene}

Kinases are essential molecules in signaling processes, and thus, we searched for kinases implicated in immune responses using a microarray analysis of transcriptional responses to $A$. brassicicola infection. A. brassicicola inoculation led to the identification of 224 genes with differential expression ( $\geq 2$-fold change; $P<0.05$; Table S2), which included 10 genes encoding distinct types of kinases (Table S3). Recent studies have demonstrated the implications of CRKs to immune responses (Wrzaczek et al., 2010; Bourdais et al., 2015; Yeh et al., 2015), and thus, we chose CRK36 (At4g04490) for further study.

We initially examined CRK36 expression in response to SA, methyl jasmonate (MeJA), and ethephon (ET), the ethylene releaser, using $P R 1, P D F 1.2$, and GLIP1 as positive controls (Figure S1A; Kim et al., 2013). CRK36 was highly expressed in leaves after hormone treatments. Tissue-specific expression was then assessed in transgenic Arabidopsis plants harboring the CRK36 promoter ( $p C R K 36$ ) fused to a $\beta$-glucuronidase (GUS) reporter gene. GUS staining showed expression in the hypocotyls and roots of seedlings (5 DAG), older (14 DAG), and senescing (36 DAG) leaves, and hydathodes at all growth stages (Figure S1B). GUS activity was also detected in reproductive organs such as sepals and septum tips. We then tested the responses of $p C R K 36$ :GUS plants to pathogen infection (Figure S1C). GUS signals were greatly increased upon treatments with pathogens including $A$. brassicicola, virulent and avirulent strains of P. syringae, Pst DC3000 and Pst DC3000 (AvrRpm1), suggesting that $C R K 36$ is involved in pathogenic responses.

To study the function of CRK36, we obtained 3 different T-DNA insertion lines (SALK_035659; crk36-1, SALK_100834; crk36-2, and SALK_116300; crk36-3) that carry T-DNA insertions in the CRK36 promoter region (Figure S2A). In the qRT-PCR analysis, CRK36 mRNAs were still detectable in these mutant lines with $30-50 \%$ reduction of transcripts, indicating that they were knockdown mutants (Figure S2B). We also prepared transgenic plants $(C R K 36 O E)$ overexpressing CRK36 under the control of the CaMV $35 \mathrm{~S}$ promoter in which CRK36 transcript levels were significantly increased (Figure S2C).

\section{CRK36 Regulates Cell Death, ROS Production, and Disease Resistance in Response to Necrotrophic Pathogens}

We investigated how crk36 and CRK36OE plants respond to pathogen infection. Since CRK36 was identified as an A. brassicicola-responsive gene, plants were first challenged with $A$. brassicicola and assessed for disease development. In CRK36OE plants, necrotic cell death symptoms were enhanced, as indicated by increased lesion size (Figures 1A,B). The extent of cell death was further confirmed by trypan blue staining that marks dead cells (Figure 1C). In contrast, reduction 
of $A$. brassicicola-induced cell death and disease symptoms was observed in crk36 knockdown lines. For quantitative evaluation of A brassicicola growth, the spore number and abundance of fungal DNA (internal transcribed spacers, ITS) were determined in the infected leaves. CRK36OE plants displayed susceptible phenotypes with increased spore number and ITS abundance (Figure 1B, Figure S3). We additionally tested susceptibility of crk36-2 and CRK36OE plants to the compatible necrotrophic bacterial pathogen Erwinia carotovora. Compatible interaction developed in wild type plants, and it was enhanced in CRK36OE plants but suppressed in crk36-2 plants (Figure S4).

We next carried out DAB staining to test whether cell death was correlated with ROS accumulation in the infected leaves. ROS production was greatly increased in CRK36OE plants but decreased in crk36-2 plants following A. brassicicola inoculation (Figures 1D,E). As an initial step to explore the function of CRK36, we analyzed ATTED-II (http://atted.jp/), a gene coexpression database that provides information on gene interactions and coregulated gene networks (Figure S5; Obayashi et al., 2007). The list of coexpressed genes of CRK36 included redox system-related genes such as alternative oxidase $1 D(A O X 1 D)$ and glutathione S-transferase TAU 3 (GSTU3) (Dixon et al., 2002; Konert et al., 2015). In the qRT-PCR analysis, $A O X 1 D$ and GSTU3 were both induced in wild type plants by $A$. brassicicola treatment (Figure 1F). In accordance with the positive correlation between CRK 36 and ROS production, their expression further increased in CRK36OE, but decreased in crk36-2 plants. These results suggest that CRK36 may be implicated in cell death and redox regulation during immune responses.

\section{CRK36 Regulates Cell Death, ROS Production, and Disease Resistance in Response to Hemibiotrophic Pathogens}

Among the tested independent lines, crk36-2 and CRK36OE(\#5) were chosen for further analysis. We next challenged plants with virulent and avirulent bacterial pathogens Pst DC3000 and Pst DC3000 (AvrRpm1). In contrast to the resistance response to $A$. brassicicola, disease symptoms were more severe in crk36-2 plants but were reduced in CRK36OE plants upon Pst DC3000 infiltration, which correlated with bacterial growth (Figures 2A,B). Similar bacterial growth results were obtained with Pst DC3000 (AvrRpm1) (Figure 2D). As observed upon A. brassicicola infection, HR PCD developed more strongly in Pst DC3000 (AvrRpm1)-infiltrated CRK36OE leaves but more weakly in crk36-2 than in wild type (Figure 2C). Cell death phenotypes of plants were confirmed by trypan blue staining and electrolyte leakage assay (Figure 2E, Figure S6). Consistently, significant induction of pathogenesis-related (PR) genes $P R 1, P R 2$, and $P R 5$ was observed in CRK36OE plants in response to both Pst DC3000 and Pst DC3000 (AvrRpm1); this was reversed in crk36-2 plants (Figure S7). Another avirulent bacterial pathogen Pst DC3000 (AvrRpt2) was also tested. Pst DC3000 (AvrRpt2) infiltration evoked HR cell death and trypan blue staining patterns in the infected crk36-2 and CRK36OE leaves similarly to Pst DC3000 (AvrRpm1) (Figure S8A).

ROS production is an early response of $\mathrm{HR}$, and has been attributed to NADPH oxidases (Tang et al., 1998; Torres et al., 2002, 2006). Thus, we monitored ROS production in plants challenged with either Pst DC3000 (AvrRpm1) or Pst DC3000 (AvrRpt2) by DAB staining. CRK36OE plants accumulated more DAB-stained ROS than wild type, whereas crk36-2 plants showed lower ROS production (Figures 2E,F, Figures S8A,B). Treatment with diphenylene iodonium (DPI), an NADPH oxidase inhibitor, reduced avirulent pathogen-induced ROS accumulation in all plants (Figure 2F, Figure S8B), which agreed with previous reports that NADPH oxidases are the primary ROS-generating system during incompatible plant-pathogen interactions. These results suggest that CRK36 positively regulates HR cell death, its associated ROS production, and ultimately, ETI responses.

\section{Function of CRK36 in Cell Death Processes}

We investigated whether CRK36 is also implicated in other PCD processes. Plants were treated with the PCD-eliciting fungal toxin fumonisin B1 (FB1) (Kwon et al., 2009). As observed with pathogen infection, the extent of FB1-triggered cell death was increased in FB1-treated CRK36OE leaves, in contrast to crk36-2 leaves, which showed reduced cell death lesions (Figure S9A). In addition, we determined the involvement of CRK36 in leaf senescence, a developmental PCD process (Quirino et al., 2000; Lim et al., 2007). During dark-induced senescence, GUS expression driven by $p C R K 36$ gradually increased, and yellowing was accelerated in CRK36OE leaves but delayed in crk362 leaves (Figures S9B,C). Age-dependent leaf senescence was also monitored. CRK36OE plants exhibited an early-senescence phenotype, which was delayed in crk36-2 leaves (Figure S9D). These results suggest that CRK36 is involved in various types of PCD processes in plants.

\section{CRK36 Regulates PTI Responses}

It was then investigated whether CRK36 plays a role in PTI responses, including ROS production, callose deposition, and gene expression. We first examined CRK36 activation in response to a typical PAMP flg22. Transcriptional response of CRK36 to flg22 was rapid, as GUS signals were detected in pCRK36:GUS plants $5 \mathrm{~min}$ after flg22 treatment (Figure 3A). ROS production, callose deposition, and expression of PTI responsive genes FRK1 and WRKY29 were markedly increased in flg22-treated $C R K 36 O E$ plants but somewhat decreased in crk36-2 plants as compared to that in wild type plants (Figures 3B-D). Stomatal closure is an essential PTI response, known as stomatal immunity, that is triggered by a PAMPtriggered ROS burst (Melotto et al., 2006). In line with flg22triggered ROS production, flg22 treatment induced stomatal closure in wild type plants, and this was impaired in crk362 mutant (Figure 3E). However, in CRK36OE plants, stomata were more strongly closed after flg22 treatment. While stomatal closure is an important early event to prevent bacterial entry, Pst DC3000 promotes the re-opening of stomata and thus the invasion of leaf tissues (Zeng and He, 2010). We measured stomatal apertures following surface-inoculation with 
A

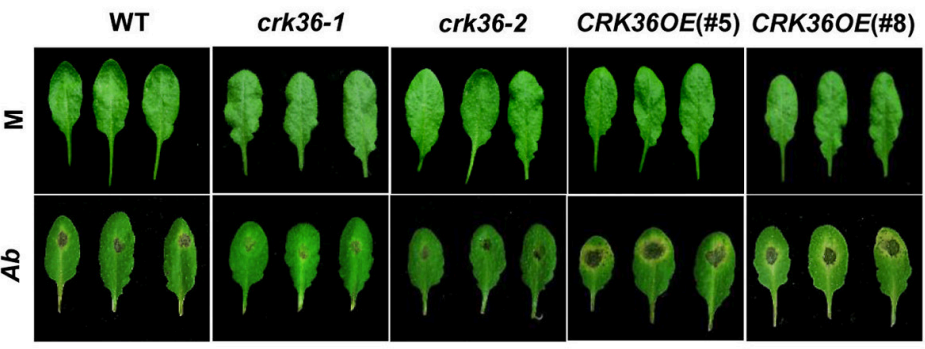

B

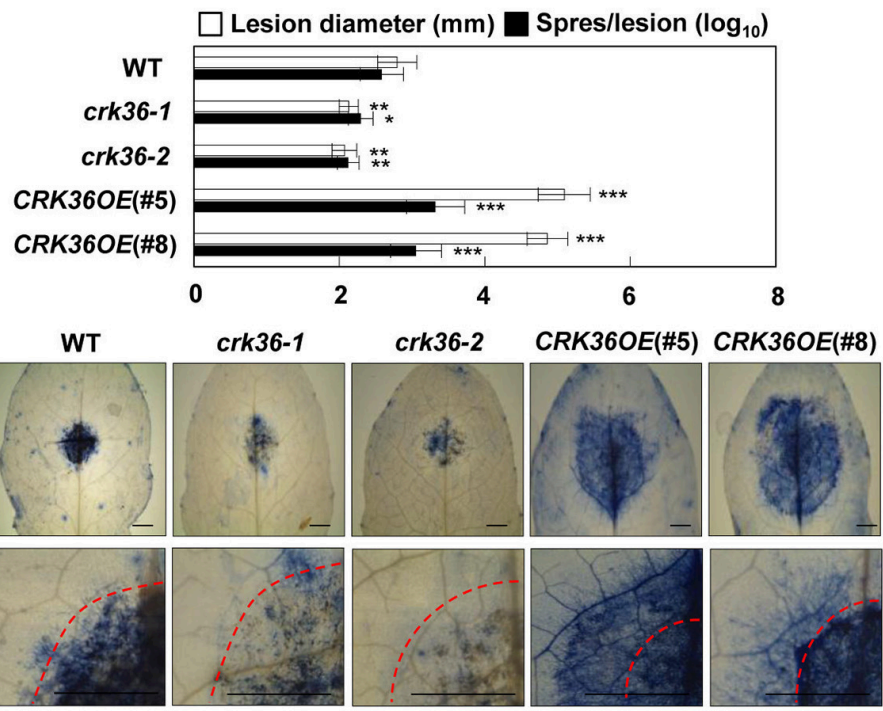

D

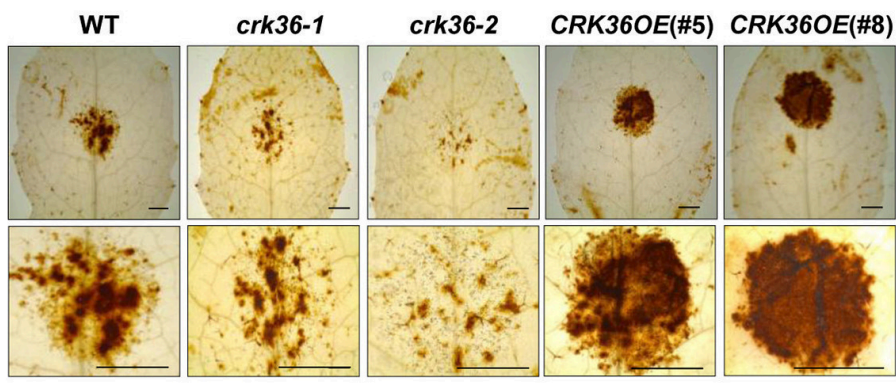

E
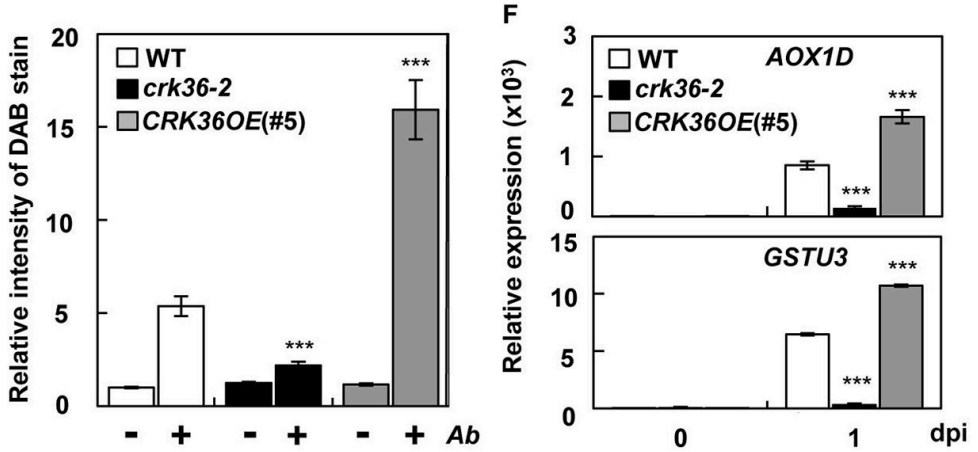

FIGURE 1 | Responses of crk36 and CRK36OE plants to the fungal pathogen A. brassicicola. (A) Disease symptoms in leaves inoculated with A. brassicicola. (B) Measurements of lesion diameter and spore number in leaves. Values are means \pm SD $(n=6)$. (C) Necrotic lesions in leaves stained with trypan blue. Dashed red lines indicate the inoculation areas. (D) ROS production in leaves as determined by DAB staining. (E) Quantification of DAB-stained ROS in (D). Values are means \pm SD $(n=6)$. (F) qRT-PCR analysis of AOX1D and GSTU3 expression. Results represent means $( \pm$ SD) of 3 biological replicates. Leaves were inoculated with water (mock) or fungal spore suspension $\left(1 \times 10^{6}\right.$ spores $\left./ \mathrm{mL}\right)$ for 6 days in $(\mathbf{A}-\mathbf{E})$ or 1 day in $\mathbf{( F )}$. Asterisks indicate significant differences from $W T\left(t\right.$-test; ${ }^{*} P<0.05$; $\left.{ }^{\star \star} P<0.01 ;{ }^{\star \star \star} P<0.001\right)$. Experiments were repeated 3 times with similar results. $\mathrm{M}$, mock. Ab, A. brassicicola. dpi, days post-inoculation. Bars, $5 \mathrm{~mm}$. 
A

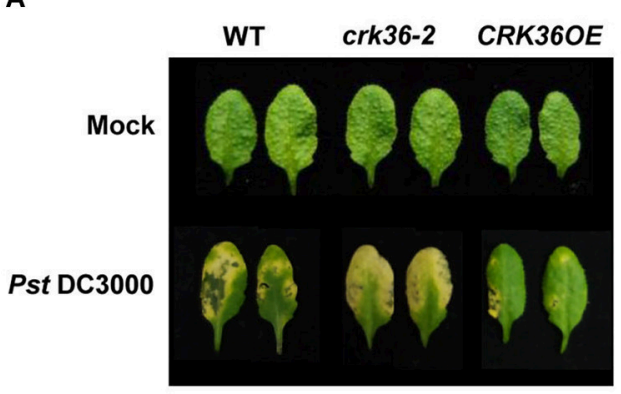

C

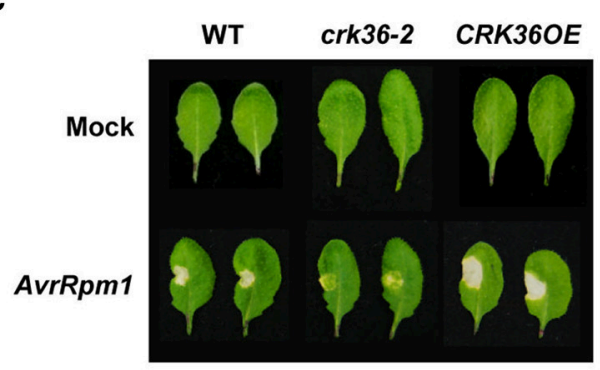

E

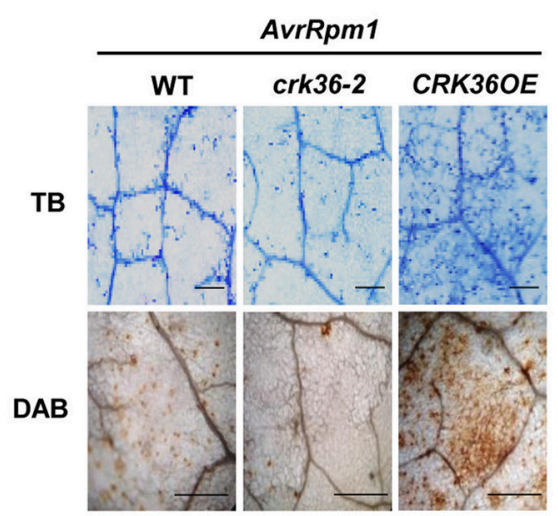

B

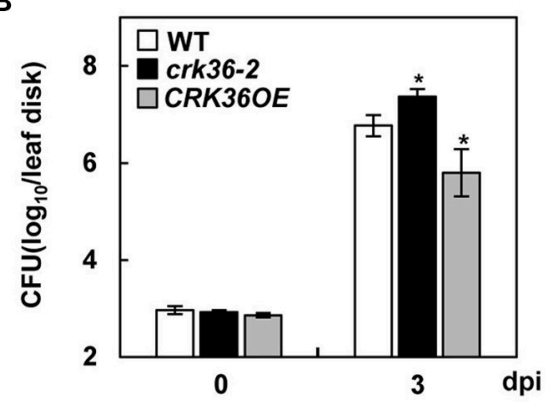

D

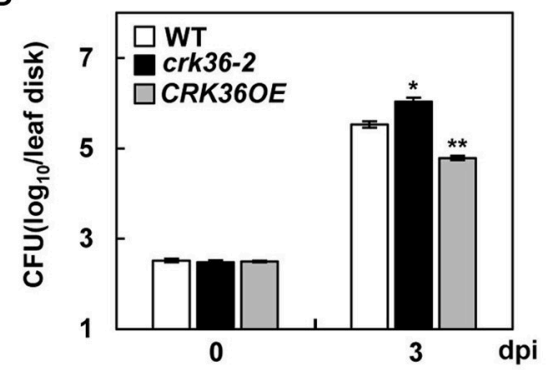

F

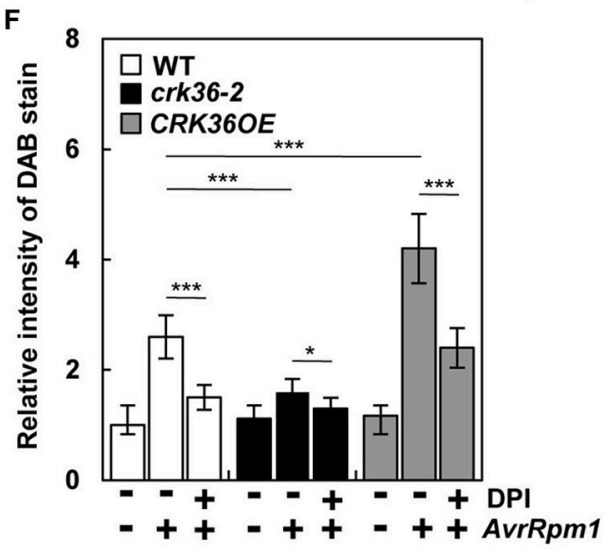

FIGURE 2 | Responses of crk36 and CRK36OE plants to the bacterial pathogens Pst DC3000 and Pst DC3000 (AvrRpm1). (A,C) Disease symptoms in leaves inoculated with Pst DC3000 (A) and Pst DC3000 (AvrRpm1) (C). (B,D) Bacterial growth in leaves inoculated with Pst DC3000 (B) and Pst DC3000 (AvrRpm1) (D). Values are means \pm SD $(n=9)$. (E) Cell death determined by trypan blue (TB) staining (top) and ROS production by DAB staining (bottom) after Pst DC3000 (AvrRpm1) treatment. (F) Quantification of DAB-stained ROS in (E) and DPI effect on ROS production after Pst DC3000 (AvrRpm1) treatment. Leaves were pre-treated with $10 \mu \mathrm{M}$ DPI for $1 \mathrm{~h}$ and then infected with pathogens. Values are means \pm SD $(n=6)$. Leaves were inoculated with Pst DC3000 or Pst DC3000 (AvrRpm1) at $1 \times 10^{6} \mathrm{cfu} / \mathrm{mL}$ for 3 days in (A-D) and with Pst DC3000 (AvrRpm1) at $1 \times 10^{7} \mathrm{cfu} / \mathrm{mL}$ for 1 day in (E,F). Asterisks indicate significant differences from WT in (B,D,F) and between untreated and DPI-treated plants in (F) $\left(t\right.$-test; $\left.{ }^{*} P<0.05 ;{ }^{* *} P<0.01 ;{ }^{* * \star} P<0.001\right)$. Experiments were repeated 3 times with similar results. dpi, days post-inoculation.

Pst DC3000. Stomatal closure of plants incubated with pathogens for $1 \mathrm{~h}$ was similar to that induced by flg22 (Figure 3F). Stomatal re-opening was observed $4 \mathrm{~h}$ after exposure to Pst DC3000, and was more pronounced in crk36-2 mutant but completely abolished in CRK36OE plants. Following surface inoculation with Pst DC3000, bacterial populations were higher in CRK36OE leaves but lower in crk36-2 mutant than in wild type plants (Figure 3G). We additionally prepared transgenic plants $\left(C R K 36^{\mathrm{K} 386 \mathrm{E}} \mathrm{OE}\right)$ overexpressing a kinasedead CRK36 ${ }^{\mathrm{K} 386 \mathrm{E}}$ mutant form in which the conserved Lys386 was replaced by Asp (Figure S10A). Overexpression of $C R K 36^{\mathrm{K} 386 \mathrm{E}}$ attenuated flg22-induced stomatal closure
(Figure 3H), suggesting that $\mathrm{CRK} 36^{\mathrm{K} 386 \mathrm{E}}$ exerts a dominant negative effect and that CRK36 requires kinase activity for its function in basal immune responses. Together, these results demonstrate that CRK36 positively regulates PTI, including stomatal defense.

\section{Conserved Cys Residues in the DUF26 Domains Are Essential for CRK36 \\ Functions}

CRK36 contains 9 conserved Cys residues in 2 DUF26 motifs of the extracellular region: 5 in the first DUF26 motif and the other 
A

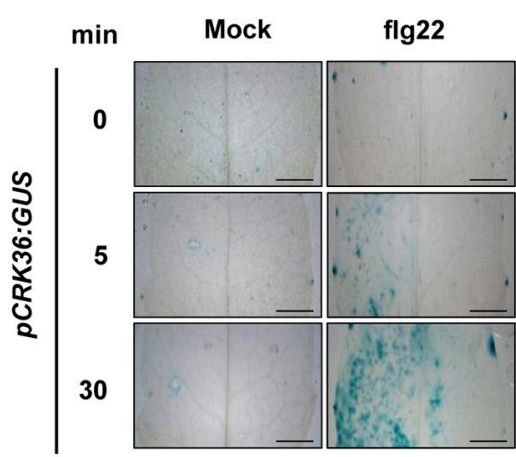

C

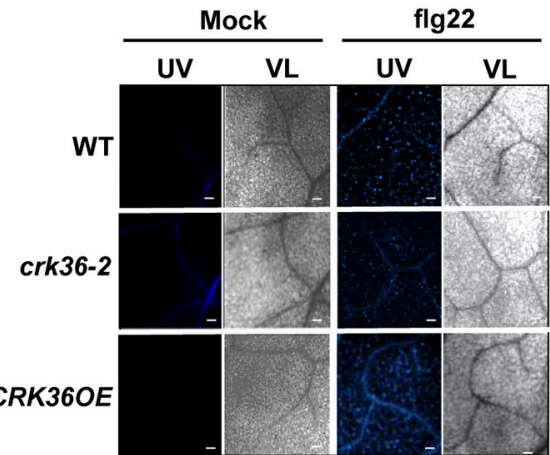

E

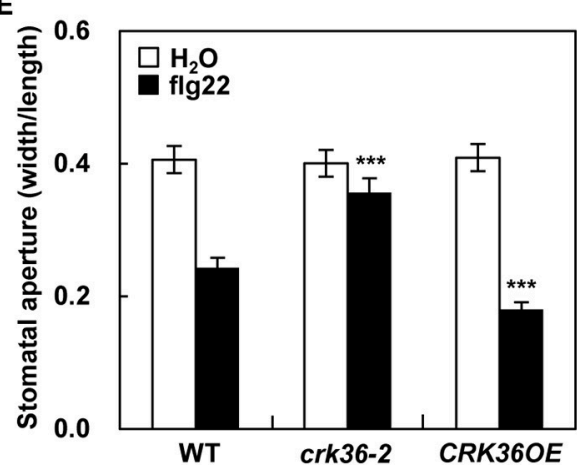

G

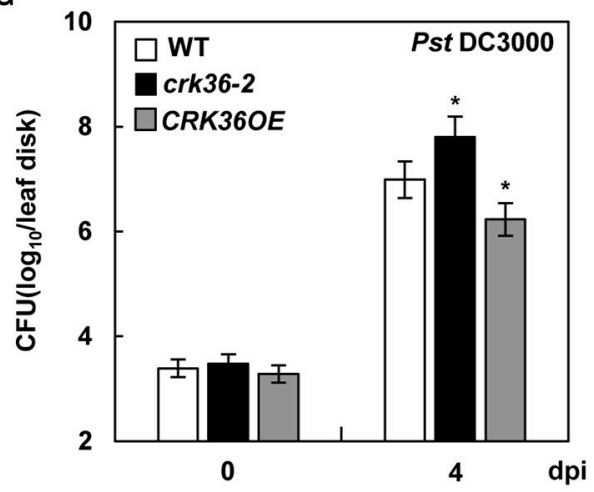

B

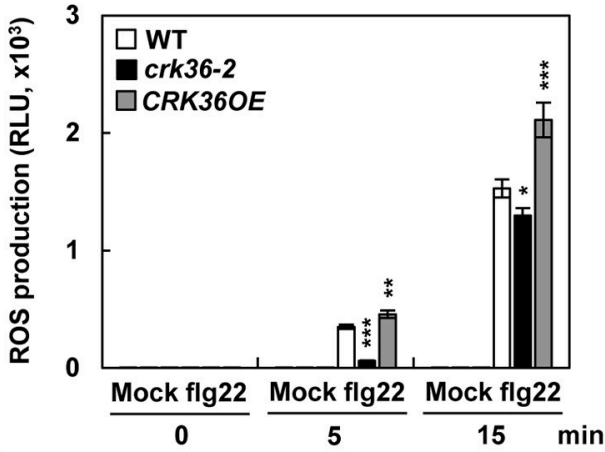

D

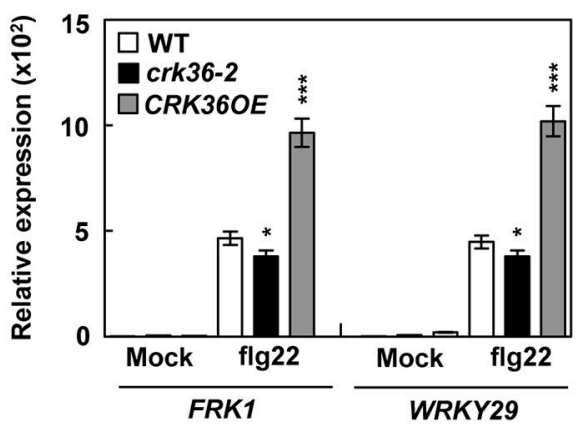

$\mathbf{F}$

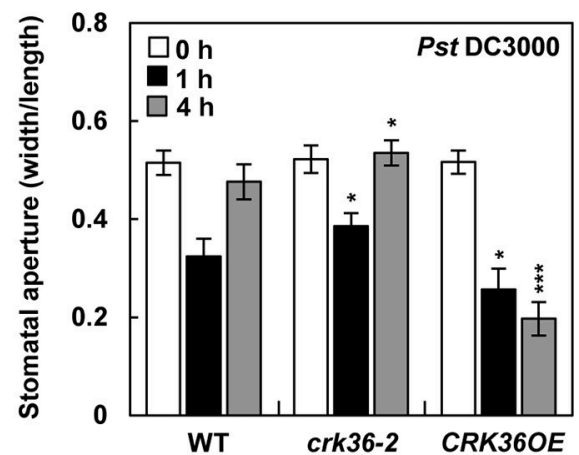

H

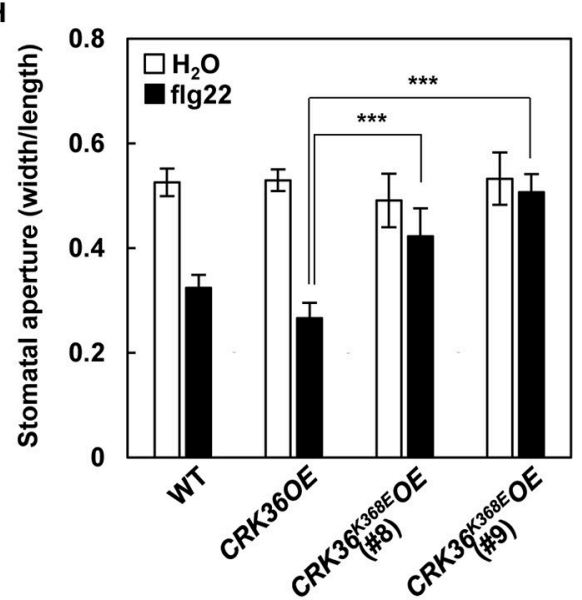

FIGURE 3 | PTI responses in crk36 and CRK36OE plants. (A) GUS activity in pCRK36:GUS leaves in response to flg22 (1 $\mu \mathrm{M})$. Bars, $1 \mathrm{~mm}$. (B) flg22-triggered oxidative burst. Leaf discs were taken from water- or flg22 (100 nM)-treated plants and monitored for ROS generation (presented as total photon count). Values are means \pm SD $(n=10)$. (C) Callose deposition. Leaves were treated with water (mock) or flg22 (1 $\mu \mathrm{M})$ for $18 \mathrm{~h}$ and stained with aniline blue. UV, ultraviolet light. VL, 


\section{FIGURE 3 | Continued}

visible light. Bars, $100 \mu \mathrm{m}$. (D) qRT-PCR analysis of PTI marker genes FRK1 and WRKY29. Results represent means ( \pm SD) of 3 biological replicates. (E) flg22-induced stomatal movement. Stomatal apertures were measured in epidermal peels floated in MES buffer containing flg22 $(1 \mu \mathrm{M})$ for $2 \mathrm{~h}$. Values are means \pm SD $(n=60)$.

(F) Pathogen-induced stomatal movement. Stomatal apertures were measured in epidermal peels of plants after spray-inoculation with Pst DC3000 (1 $\left.\times 10^{8} \mathrm{cfu} / \mathrm{mL}\right)$. Values are means $\pm \mathrm{SD}(n=60)$. (G) Bacterial growth in leaves spray-inoculated with Pst DC3000 $\left(5 \times 10^{8} \mathrm{cfu} / \mathrm{mL}\right)$. Values are means $\pm \mathrm{SD}(n=3)$. (H) flg22-induced stomatal movement in kinase-dead CRK36 transgenic plants. Stomatal apertures were measured in epidermal peels floated in MES buffer containing flg22 ( $1 \mu \mathrm{M})$ for $2 \mathrm{~h}$. Values are means $\pm \mathrm{SD}(n=60)$. Asterisks indicate significant differences from WT in $\mathbf{( C - G )}$ and from $C R K 36 O E$ in $(\mathbf{H})\left(t\right.$-test; ${ }^{*} P<0.05 ;{ }^{\star \star} P<0.01$;

$\left.{ }^{\star \star \star} P<0.001\right)$. Experiments were repeated 3 times with similar results.

4 in the second DUF26 motif (Figure 4A). As the thiol side chain in Cys is susceptible to oxidation, CRKs have been suggested as potential targets for redox regulation (Wrzaczek et al., 2010; Bourdais et al., 2015). To explore the role of these conserved Cys residues, we made 2 mutant constructs, CRK36 ${ }^{\mathrm{C} 12345 \mathrm{~A}}$ and CRK36 ${ }^{\text {C6789A }}$, in which 5 and 4 Cys residues of the first and second DUF26 motifs, respectively, were changed to Ala residues. We then prepared transgenic Col-0 plants overexpressing them (CRK36 ${ }^{\mathrm{C} 12345 \mathrm{~A}} \mathrm{OE}$ and $C R K 36^{C 6789 \mathrm{~A}} \mathrm{OE}$ ) (Figure S10B). Among these, CRK36 ${ }^{\mathrm{C} 12345 \mathrm{~A}} \mathrm{OE}(\# 6)$ and $C R K 36^{C 6789 A} \mathrm{OE}(\# 1)$ were used for further analysis. When inoculated with either A. brassicicola or Pst DC3000 (AvrRpm1), the enhancement of hypersensitive cell death lesions and ROS production in CRK36OE plants was not observed in $C R K 36^{C 12345 A} O E$ and $C R K 36^{C 6789 A} O E$ leaves, which exhibited hypersensitive responses similar to those in wild type (Figures 4B,C). We also tested whether Cys mutations affected PTI responses. Likewise, positive effects of CRK36 overexpression on flg22-induced ROS burst and stomatal closure were abolished in $C R K 36^{C 12345 A} O E$ and CRK36 ${ }^{\mathrm{C} 6789 \mathrm{~A}} \mathrm{OE}$ plants (Figures 4D,E). These results suggest that Cys residues in the DUF26 domains are essential for CRK36 functions in PTI and ETI, particularly in ROS production events.

\section{CRK36 Physically Interacts With BIK1}

Since CRK36 plays a positive role in flg22-induced PTI, we investigated whether CRK36 interacts with the components of the flg22-sensing PRR complex, including FLS2, BAK1, and BIK1, in yeast two-hybrid assay. Chitin elicitor receptor kinase 1 (CERK1), a different PRR, was also included in the analysis. In the yeast two-hybrid system, the interacting proteins are located in the nucleus, and membrane proteins may form aggregates without membranes being provided. For this reason, we used the intracellular kinase domains of CRK36 and PRRs instead of the entire coding region. CRK36 and tested proteins fused to the GAL4-activation domain (AD) and DNA-binding domain (BD) were expressed pairwise in yeast cells (Figure 5A). Of these, yeast cells co-transformed with AD-BIK1 and BD-CRK36 constructs were able to grow on selective medium lacking adenine, histidine, leucine, and tryptophan, and turned blue in the presence of X$\alpha$-Gal, implying a direct interaction between CRK36 and BIK1. No interactions were observed between CRK36 and the other tested proteins, FLS2, CERK1, and BAK1. Expression of proteins was validated by western blotting of yeast cell extracts using antiHA and anti-Myc antibodies (Figure S11). GST pull-down assay confirmed the in vitro interaction between CRK36 and BIK1 (Figure 5B).
To further evaluate the interaction in vivo, we carried out bimolecular fluorescence complementation (BiFC) experiments using full-length proteins. The constructs of BIK1 fused with the $\mathrm{N}$-terminal part of YFP $\left(\right.$ BIK1-YFP $\left.{ }^{\mathrm{N}}\right)$ and CRK36 fused with the C-terminal part of YFP (CRK36-YFPC ${ }^{\mathrm{C}}$ were prepared, and singly or in combination transiently expressed in N. benthamiana leaves (Figure S12). YFP fluorescence was only detected when BIK1YFP $^{\mathrm{N}}$ and CRK36-YFP ${ }^{\mathrm{C}}$ were co-expressed. Their interaction was further observed by the co-immunoprecipitation of BIK1 and CRK36 in tobacco leaf extracts (Figure 5C). While we were conducting this study, a report was released demonstrating that CRK36 associates with FLS2 in Arabidopsis protoplasts as shown by BiFC assay (Yeh et al., 2015). Therefore, BiFC assays were additionally performed in Arabidopsis protoplasts to assess the interactions of CRK36 with FLS2 and BIK1. In agreement with the former result, an YFP signal was observed in protoplasts co-transformed with FLS2-YFP ${ }^{\mathrm{N}}$ and CRK36-YFP ${ }^{\mathrm{C}}$ (Figure 5D). Co-expression of BIK1-YFP ${ }^{\mathrm{N}}$ and CRK36-YFP ${ }^{\mathrm{C}}$ also produced YFP fluorescence in the plasma membrane, and this signal was somewhat enhanced by flg22 treatment (Figure 5E). These results suggest that the intracellular kinase domains are not sufficient for the interaction between CRK36 and FLS2 and that CRK36, FLS2, and BIK1 are associated together in plants.

\section{CRK36 Functionally Interacts with BIK1 for Stomatal Defense}

It has been previously demonstrated that FLS2-BAK1-associated BIK1 is phosphorylated upon flagellin perception and in turn phosphorylates the NADPH oxidase, enhancing ROS generation (Lu et al., 2010; Kadota et al., 2014; Li et al., 2014). Accordingly, the interaction between CRK36, FLS2, and BIK1 led us to hypothesize that the CRK36-mediated ROS burst during PTI may result from stepwise reactions, i.e., CRK36-mediated BIK1 activation, BIK1-mediated phosphorylation of NADPH oxidases, and NADPH oxidase-mediated ROS production. To test our hypothesis, we first examined whether CRK36 triggers BIK1 phosphorylation. PAMP-induced BIK1 phosphorylation has been shown by a mobility shift in western blotting (Lu et al., 2010). Protoplasts derived from wild type and CRK36OE plants were prepared and transformed with the hemagglutinin (HA)-tagged BIK1 construct. BIK1 protein expression was visualized by immunoblotting using anti-HA antibody (Figure 6A). CRK36OE protoplasts constitutively expressed marginally slower-migrating BIK1 protein, and the mobility shift was prominent upon flg22 treatment in both wild type and CRK36OE protoplasts. Treatment with calf alkaline intestinal phosphatase (CIP) 
A

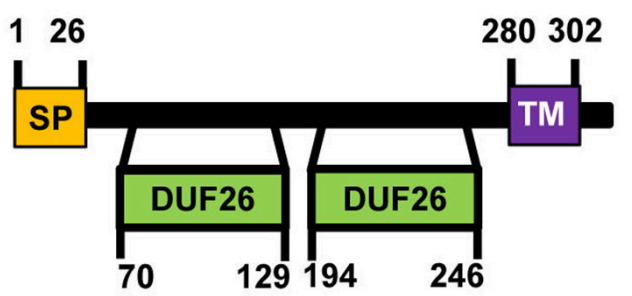

1

MERSNLFHIPCFШНШFNINGVHTTFVCGDEDFSPNTSYVNLEUPSL ASMMRERGFYNVLDGYYLALCRKHYEVQACRRCVDRASRT】TQCR GKTEAYHMDSENDANVSCLVRYSNIHRFGKLKEPIGNVPHSSLDPSN LTRISQEFAARANRTVEVASTADESSVKYYGVSSAEFIDIPEVNMLMQ CTPDLSSSDCNHCLRENVRYNOEHNMDRVGGTVARPSCYFRWDDYRF AGAFDNLRVPAPPRSPQTRQDYRVKKGRMFQPWSWWVFPTGINA VFVAFVLAYRRMRRRYTENKN $\ldots \ldots \ldots \ldots \ldots \ldots . . \ldots \ldots \ldots \ldots$

B

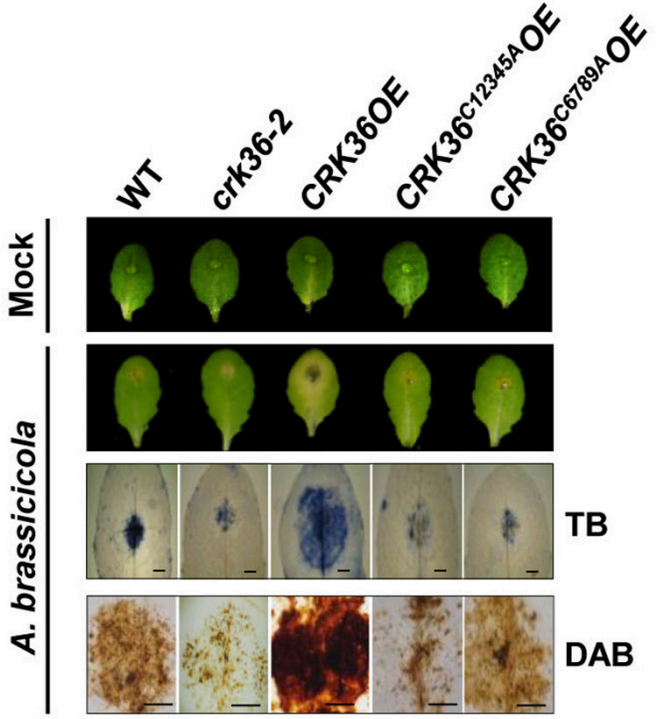

D

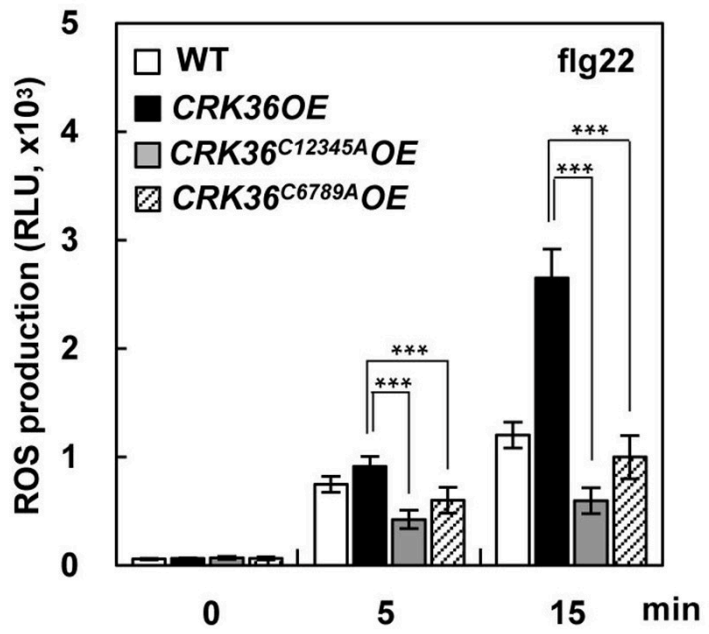

C

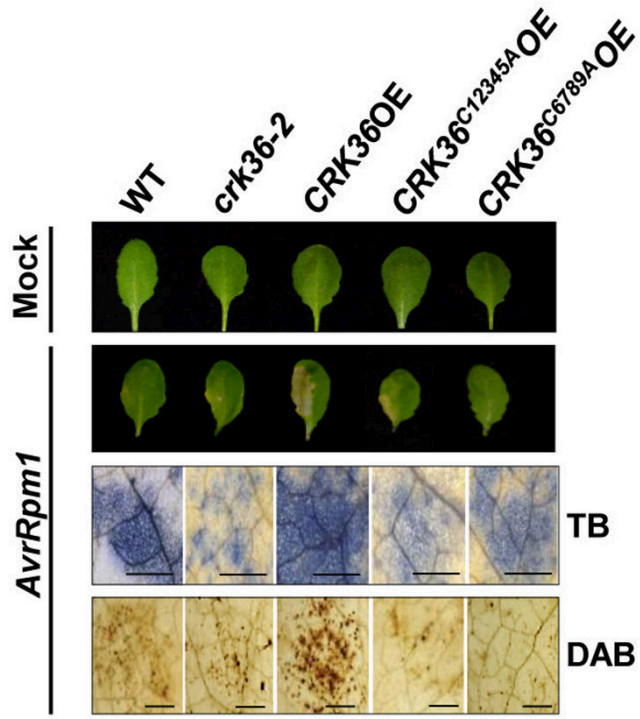

E

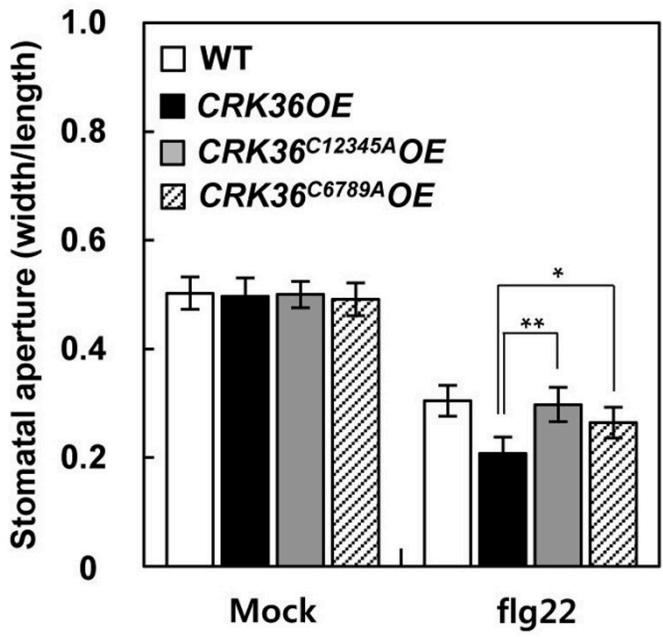

FIGURE 4 | Effect of Cys mutations in DUF26 motifs of CRK36 on immune responses. (A) Schematic structure (left) and amino acid sequence (right) of CRK36 protein. Signal peptide (SP), DUF26 motifs, transmembrane domain (TM), and conserved Cys residues are indicated in yellow, green, purple, and red colors, respectively. The diagram of the CRK36 structure was made using the EXPASY Proteomics Server PROSITE module. (B,C) Cell death and ROS production in CRK36 ${ }^{C 12345 A} O E$ and $C R K 36^{C 6789 A}$ OE plants challenged with pathogens. Phenotypes of leaves, cell death determined by trypan blue (TB) staining, and ROS production by DAB staining after A. brassicicola (B) and Pst DC3000 (AvrRpm1) (C) treatments. (D) flg22-triggered oxidative burst. Leaf discs were taken from flg22 $(100 \mathrm{nM})$-treated plants and monitored for ROS generation (presented as total photon count). Values are means $\pm \mathrm{SD}(n=9)$. (E) flg22-induced stomatal movement. Stomatal apertures were measured in epidermal peels floated in MES buffer containing flg22 $(1 \mu \mathrm{M})$ for $2 \mathrm{~h}$. Values are means \pm SD $(n=60)$. Asterisks indicate significant differences from CRK36OE (t-test; ${ }^{\star} P<0.05 ;{ }^{\star \star} P<0.01$; $\left.{ }^{\star \star \star} P<0.001\right)$. Experiments were repeated 3 times with similar results. 
A

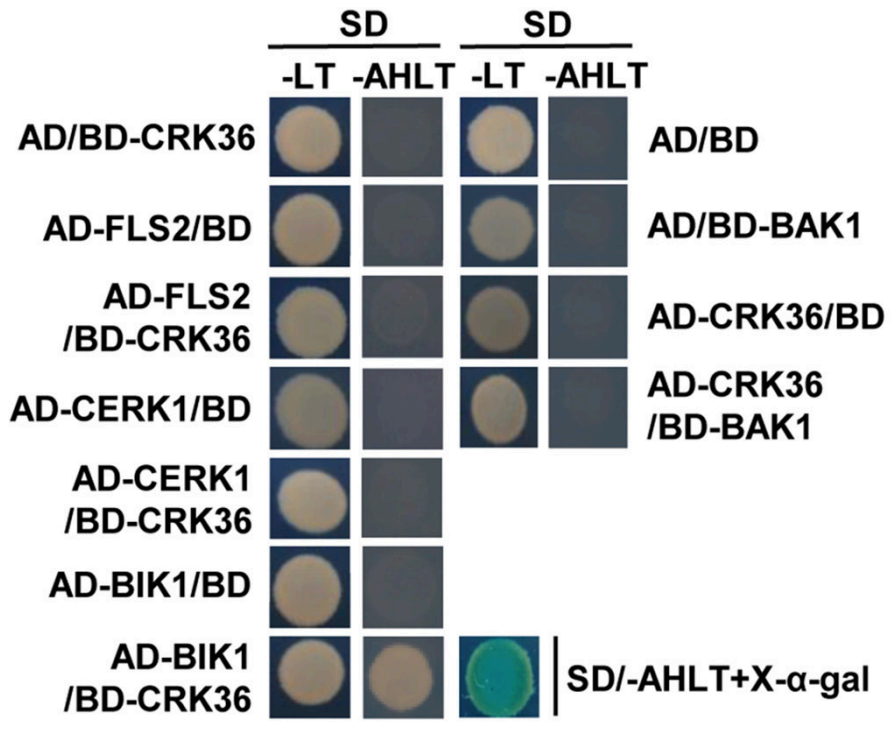

B

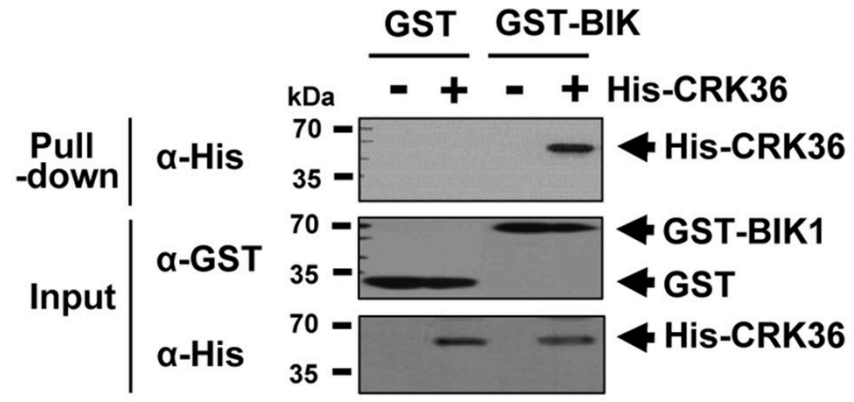

C

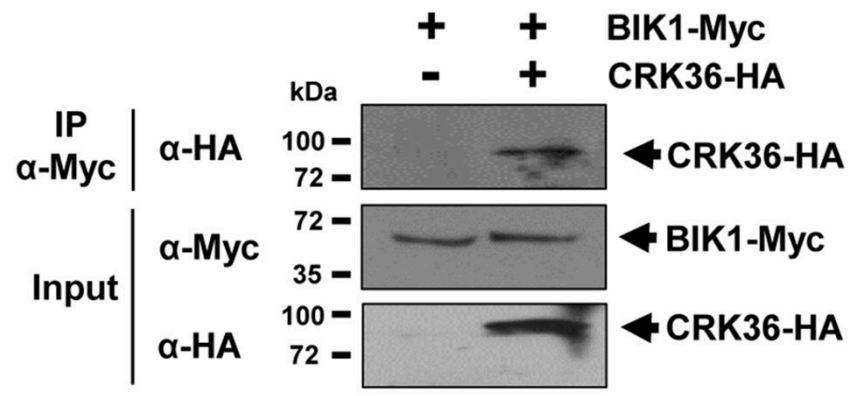

D

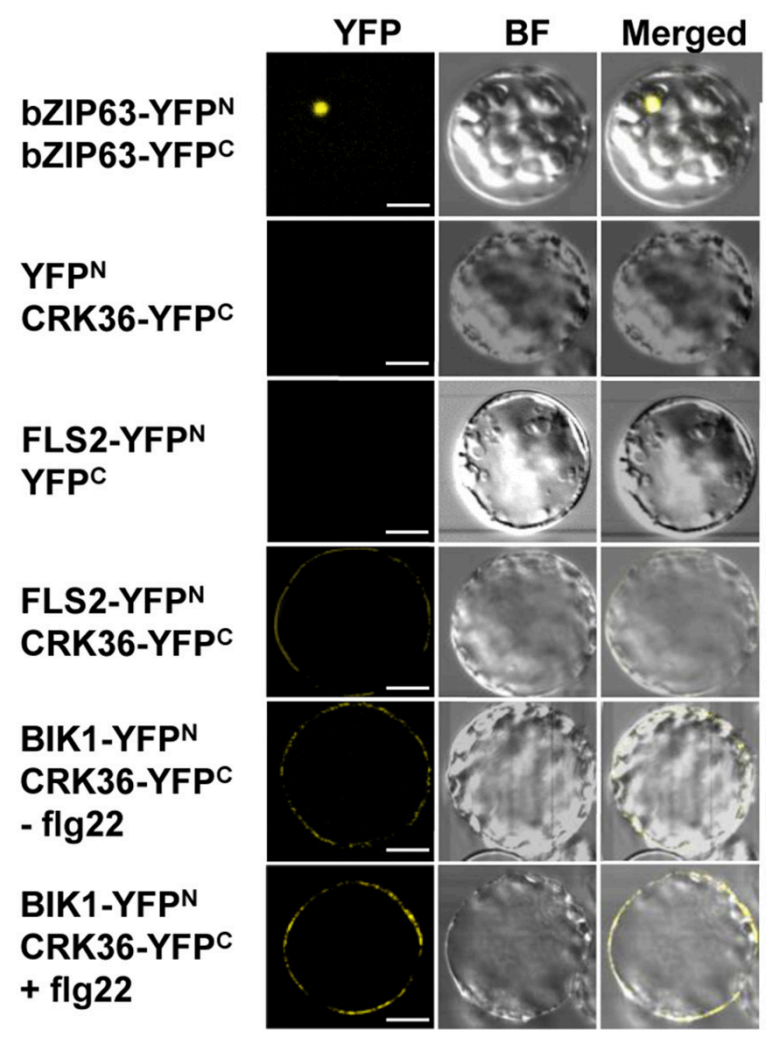

E

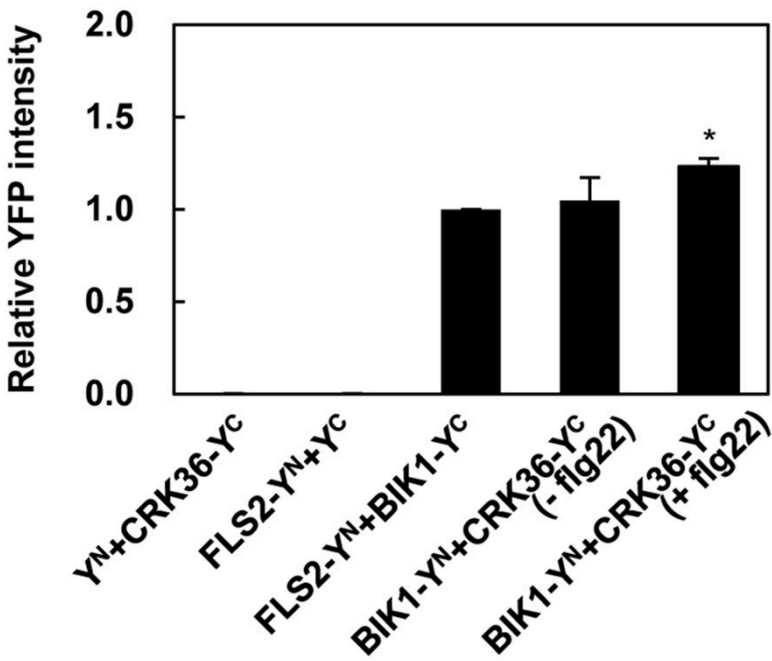

FIGURE 5 | Physical interaction between CRK36 and BIK1. (A) Yeast two-hybrid assay for interaction of CRK36 with PTI components. Cytoplasmic kinase domains of FLS2, CERK1, BAK1, and CRK36 and the full-length of BIK1 were fused with GAL4 BD or AD as indicated. Their interactions were tested on selective medium lacking adenine, histidine, leucine and tryptophan (-AHLT) in the absence or presence of X- $\alpha$-Gal. (B) In vitro GST pull-down assay for interaction between CRK36 and BIK1. GST or GST-fused BIK1 was incubated with the His-tagged kinase domain of CRK36 and precipitated with glutathione sepharose 4B beads. Proteins were detected by immunoblotting with anti-GST and anti-His antibodies. Input shows $1 \%$ of the amount used in binding reactions. (C) In vivo co-immunoprecipitation assay for interaction between CRK36 and BIK1. Protein extracts were prepared from N. benthamiana leaves expressing full-lengths of CRK36-HA and BIK1-Myc, and subjected to immunoprecipitation with anti-Myc antibody. Proteins were detected by immunoblotting with anti-HA and anti-Myc antibodies. Input shows $1 \%$ of the amount used in the binding reactions. IP, immunoprecipitation. (D) BiFC assay for interaction of CRK36 with BIK1 and FLS2 in Arabidopsis protoplasts. YFPN, YFPC, and their fusions with bZIP63, CRK36, FLS2, and BIK1 were co-expressed in Arabidopsis protoplasts for $24 \mathrm{~h}$, and then treated with $100 \mathrm{nM}$ flg22 for 15 min as indicated. Reconstituted YFP fluorescence was visualized under a confocal microscope. BF, bright field. Bars, $10 \mu \mathrm{m}$. (E) Quantitative analysis of interaction of CRK36 with BIK1 and FLS2 in (D). YFP fluorescence was quantified based on pixel intensity. Values are means \pm SD $(n=12)$. Asterisk indicates significant difference between untreated and flg22-treated BIK1-YFP + CRK36-YFPC $\left(t\right.$-test; $\left.{ }^{\star} P<0.05\right)$. $Y^{N}, Y_{F P}{ }^{N} ; Y^{C}$, YFPC . Experiments were repeated 3 times with similar results. 


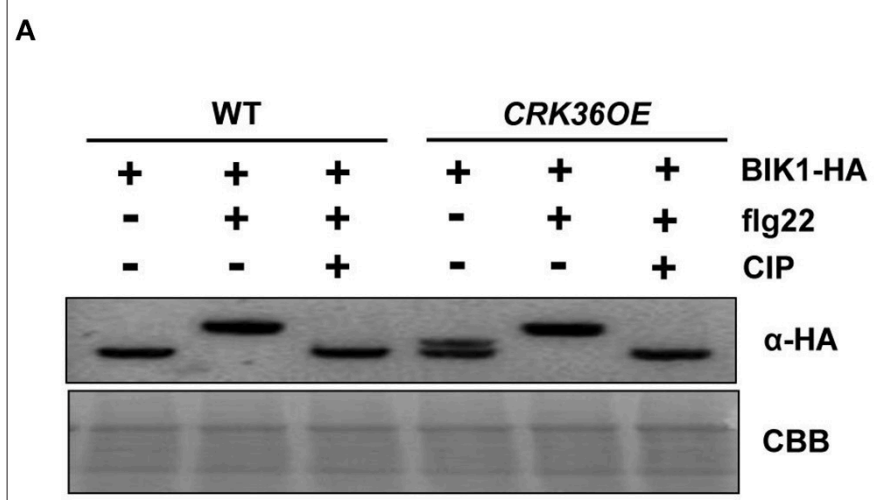

B

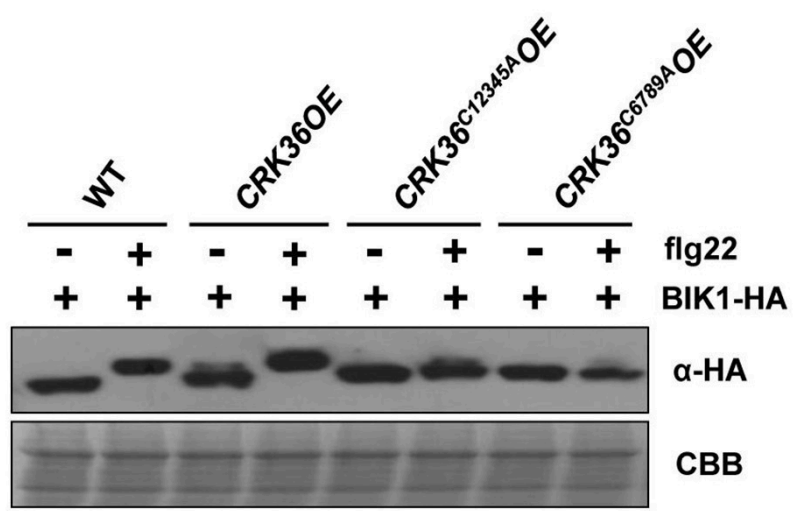

C

\section{GFP Bright field Merged}

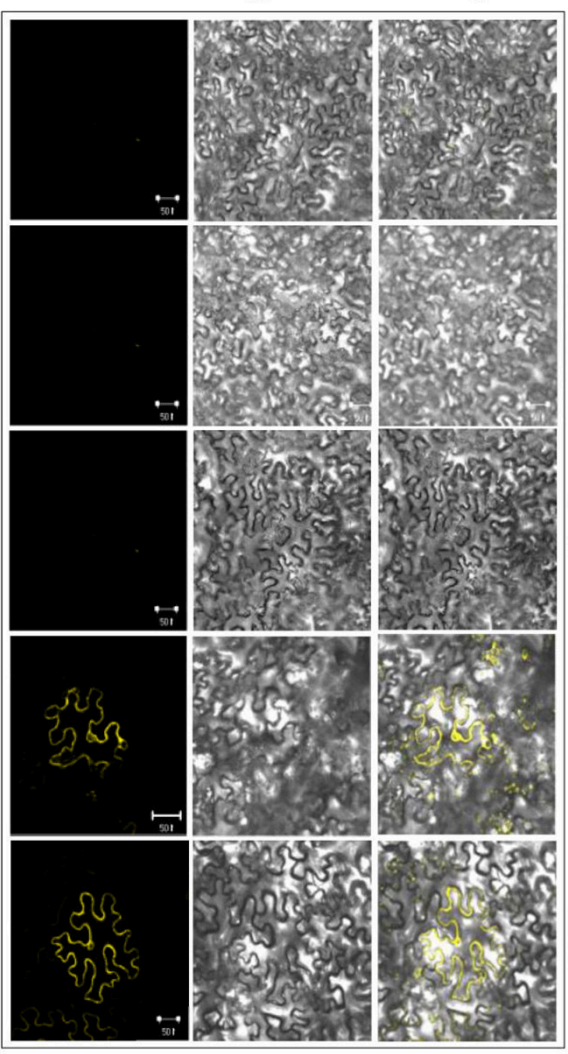

BIK1-YFPN

YFPC

YFPN
CRK36
C12345A-YFPC

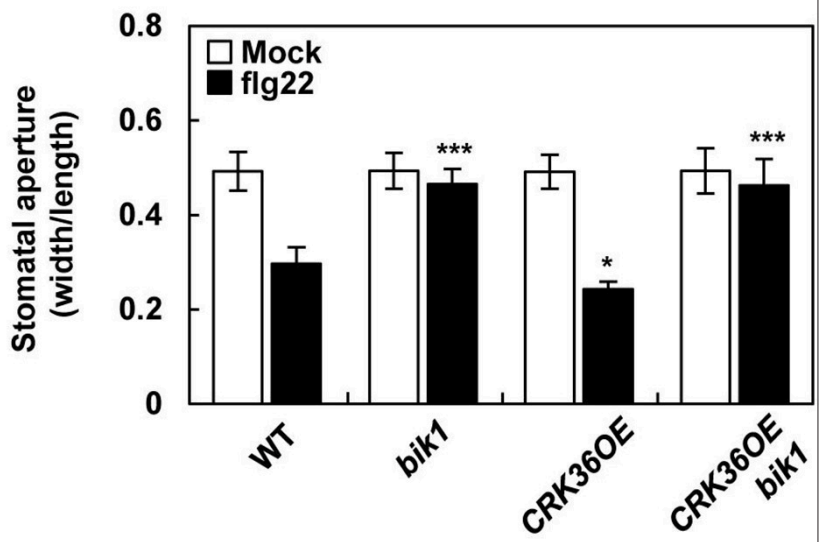

YFPN E

CRK36 ${ }^{\mathrm{C} 6789 A_{-} \text {YFPC }}$

BIK1-YFPN

CRK36 ${ }^{\mathrm{C} 12345 \mathrm{~A}}$-YFPC

\section{BIK1-YFPN}

CRK36 ${ }^{\mathrm{C} 6789 \mathrm{~A}}$-YFPC

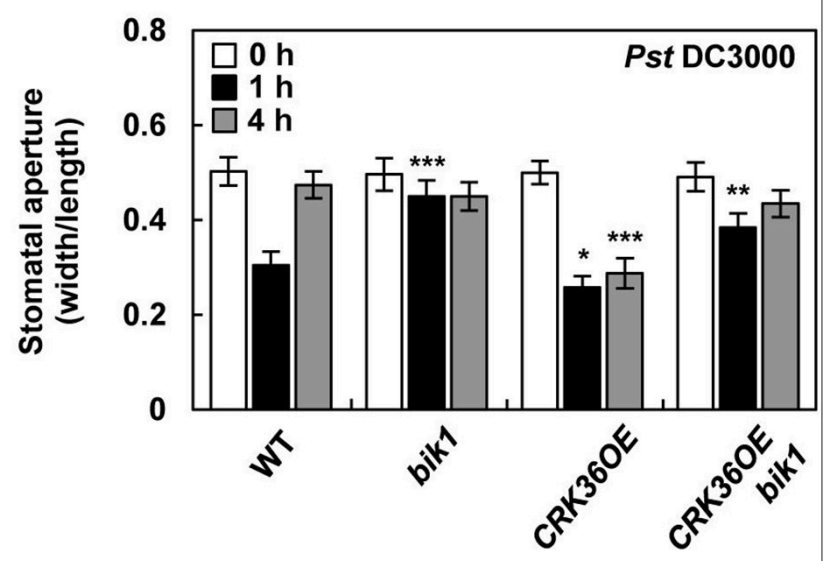

FIGURE 6 | Functional interaction between CRK36 and BIK1. (A) flg22- and CRK36-induced BIK1 phosphorylation. BIK1-HA was expressed in wild type Col-0 and CRK36OE protoplasts and treated with $1 \mu \mathrm{M}$ flg22 for $15 \mathrm{~min}$. Protein extracts were treated with calf alkaline intestinal phosphatase (CIP) for BIK1 dephosphorylation and subjected to immunoblotting with anti-HA antibody for detection of BIK1 proteins. Comassie blue staining (CBB) served as a loading control. (B) Effect of Cys mutations in DUF26 motifs of CRK36 on BIK1 phosphorylation. BIK1-HA was expressed in wild type Col-0, CRK36OE, CRK36 ${ }^{C 12345 A}$ OE, and CRK36 $6789 A$ OE protoplasts and treated with $1 \mu \mathrm{M}$ flg22 for $15 \mathrm{~min}$. Protein extracts were subjected to immunoblotting with anti-HA antibody. CBB served as a loading control.

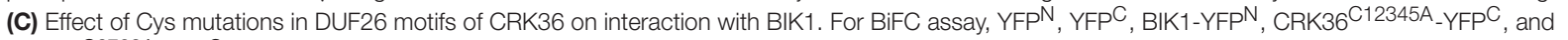
CRK36 ${ }^{\mathrm{C} 6789 \mathrm{~A}_{-} \text {YFPC }}$ were co-expressed in N. benthamiana leaves for $24 \mathrm{~h}$ as indicated. Reconstituted YFP fluorescence was visualized under a confocal microscope. Bars, $50 \mu \mathrm{m}$. (D) Effect of BIK1 mutation on flg22- and CRK36-induced stomatal closure. Stomatal apertures were measured in epidermal peels floated in MES buffer containing flg22 $(1 \mu \mathrm{M})$ for $2 \mathrm{~h}$. Values are means $\pm \mathrm{SD}(n=60)$. (E) Effect of BIK1 mutation on pathogen- and CRK36-induced stomatal closure. Stomatal apertures were measured in epidermal peels of plants after spray-inoculation with Pst DC3000 $\left(1 \times 10^{8} \mathrm{cfu} / \mathrm{mL}\right)$. Values are means $\pm \mathrm{SD}(n=60)$. Asterisks indicate significant differences from WT (t-test; ${ }^{*} P<0.05 ;{ }^{* \star} P<0.01$; $\left.{ }^{* \star} P<0.001\right)$. Experiments were repeated 3 times with similar results. 
A

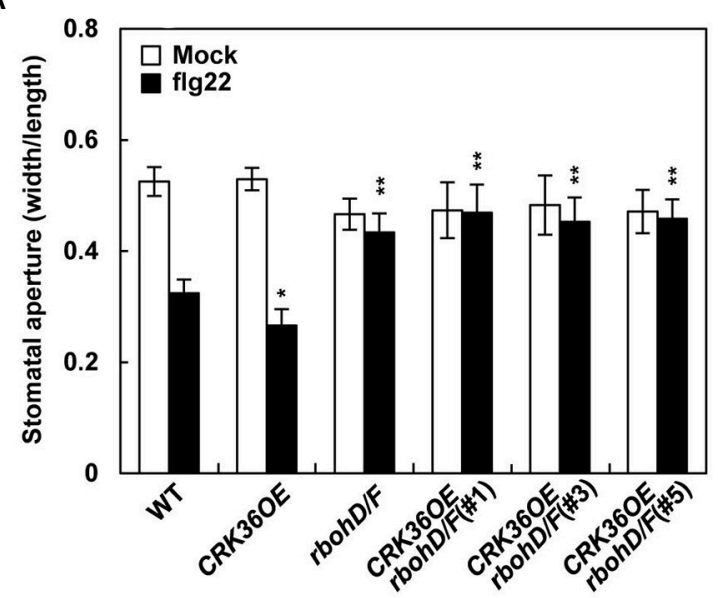

B

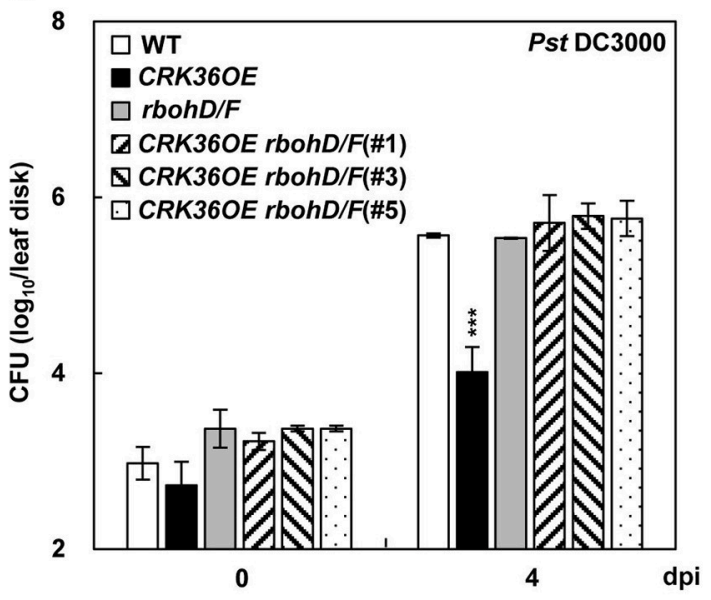

C

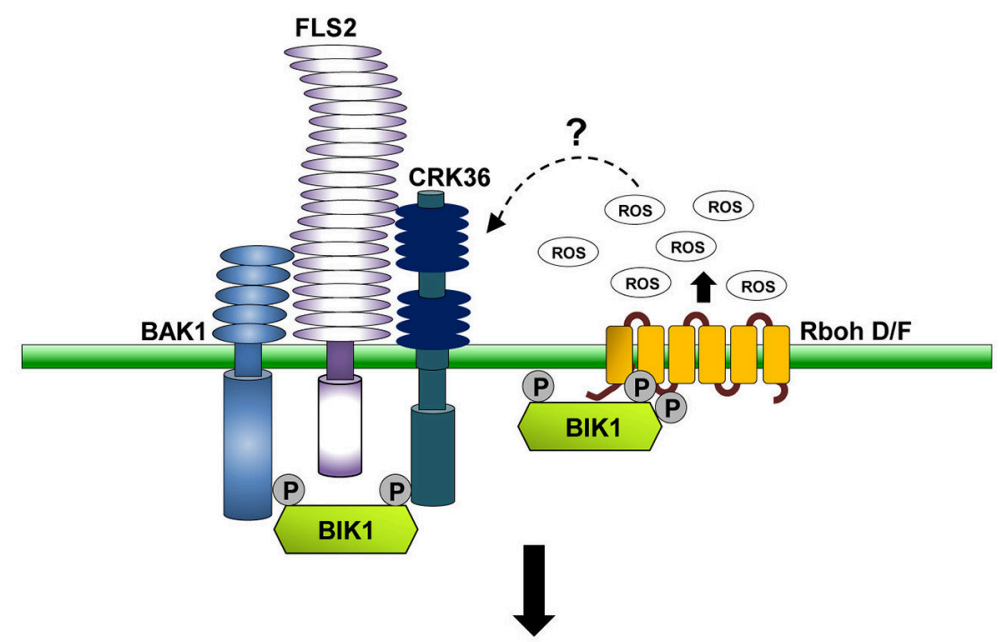

Stomatal immunity

FIGURE 7 | Stomatal immune responses in CRK36OE, rbohD/F, and CRK36OE rbohD/F plants. (A) Effect of RbohD/F mutations on flg22- and CRK36-induced stomatal closure. Stomatal apertures were measured in epidermal peels floated in MES buffer containing flg22 $(1 \mu \mathrm{M})$ for $2 \mathrm{~h}$. Values are means \pm SD $(n=60)$. Asterisks indicate significant differences from WT ( $t$-test; $\left.{ }^{*} P<0.05 ;{ }^{* *} P<0.01\right)$. (B) Effect of RbohD/F mutations on CRK36-induced pathogen resistance. Bacterial growth was determined in leaves spray-inoculated with Pst DC3000 $\left(5 \times 10^{8} \mathrm{cfu} / \mathrm{mL}\right)$. Values are means $\pm \mathrm{SD}(n=6)$. Asterisks indicate significant differences from WT ( $t$-test; ${ }^{* \star *} P<0.001$ ). (C) A model for CRK36 function in stomatal immunity. BIK1 is phosphorylated and activated when flg22 binds to the FLS2-BAK1 complex. The activated BIK1 in turn phosphorylates NADPH oxidase, triggering ROS generation. We propose that CRK36 acts as an ROS receptor that is activated by sensing ROS. The activated CRK36 enhances BIK1 phosphorylation, boosting NADPH oxidase-mediated ROS burst. CRK36, BIK1, NADPH oxidase, and ROS may form a feedback activation loop regulating stomatal defense against pathogens.

restored the mobility shift of BIK1, suggesting that CRK36 triggers BIK1 phosphorylation in PTI responses.

Given that conserved Cys residues in the DUF26 domains are essential for CRK36 functions in PTI (Figure 4), we checked the mobility of BIK1 bands in $C R K 36^{C 12345 A} \mathrm{OE}$ and $C R K 36^{\mathrm{C} 6789 A} \mathrm{OE}$ protoplasts. While similar slightly slower BIK1 was observed, flg22-induced large shift in flg22treated wild type and CRK36OE protoplasts was abolished in $C R K 36^{C 12345 A} \mathrm{OE}$ and $C R K 36^{\mathrm{C} 6789 A} \mathrm{OE}$ protoplasts (Figure 6B). Multiple phosphorylation sites have been identified in BIK1 after BIK1 autophosphorylation and BAK1 transphosphorylation reactions (Lin et al., 2014), implying that overexpression of CRK36, either in wild type or in Cys mutant forms, triggered part of BIK1 phosphorylation events. BiFC experiments were further performed by co-expressing $\mathrm{BIK} 1-\mathrm{YFP}^{\mathrm{N}}$ and either CRK36 $12345 \mathrm{~A}-\mathrm{YFP}^{\mathrm{C}}$ or CRK36 ${ }^{\mathrm{C} 6789 \mathrm{~A}}-\mathrm{YFP}^{\mathrm{C}}$ in tobacco leaves. YFP fluorescence was produced in the plasma membrane, demonstrating that Cys mutant forms of CRK36 retain the ability to associate with BIK1 (Figure 6C). These results suggest that the inability of $C R K 36^{C 12345 A} O E$ and CRK36 ${ }^{\mathrm{C} 6789 A} \mathrm{OE}$ plants to trigger PTI responses is due to the defect in BIK1 phosphorylation and that CRK36-triggered BIK1 
phosphorylation is important for the role of CRK36 in basal immunity.

To examine whether CRK36 functionally depends on BIK1, we crossed CRK36OE with bik1 mutant and determined stomatal defense. The flg22- and Pst DC3000-triggered stomatal closure and prevention of stomatal re-opening following Pst DC3000 infection observed in CRK36OE plants were impaired in CRK36OE bik1 plants (Figures 6D,E). As BIK1 regulates stomatal immunity through direct phosphorylation of the NADPH oxidase RbohD (Kadota et al., 2014; Li et al., 2014), we further crossed CRK36OE and rbohD/F (rbohD rbohF double mutant) and examined stomatal defense phenotypes. As expected, CRK36OE rbohD/F plants lost both flg22-induced stomatal closing and resistance to Pst DC3000 (Figures 7A,B). These results demonstrate that BIK1 and NADPH oxidases are required for CRK36 function in stomatal immunity.

\section{DISCUSSION}

Using cDNA microarray analysis, we identified CRK36 as an A. brassicicola-responsive gene. CRK36OE plants showed enhanced cell death and ROS production in response to avirulent pathogens including $A$. brassicicola. Disease resistance to Pst DC3000 was increased in CRK36OE plants and this was associated with NADPH oxidase-mediated ROS burst and stomatal closure. CRK36 directly interacted with and required BIK1 for stomatal defense, and further triggered BIK1 phosphorylation. Our results suggest that CRK36 plays an essential role in innate immunity through the regulation of ROS production in a BIK1- and NADPH oxidase-dependent manner.

\section{Disease Resistance and Cell Death}

CRKs form one of the largest RLK subfamilies, and play important roles in the regulation of defense responses and PCD in Arabidopsis (Chen et al., 2003; Acharya et al., 2007; Ederli et al., 2011). In previous reports, Arabidopsis plants overexpressing CRK genes enhanced resistance to Pst DC3000 and activated rapid HR cell death, suggesting that CRKs function as positive regulators in disease resistance (Acharya et al., 2007; Zhang et al., 2013; Yeh et al., 2015). While the involvement of CRKs in resistance to necrotrophic fungal pathogens has not previously been studied, microarray analysis showed that the expression of a number of $C R K s$, including CRK36, was altered by treatments with fungal pathogens, the biotrophic powdery mildew Golovinomyces orontii and the non-host powdery mildew Blumeria graminis f. sp. hordei (Bourdais et al., 2015).

In our study, CRK36 was transcriptionally regulated by A. brassicicola, and CRK36OE plants were susceptible to $A$. brassicicola and E. carotovora, in contrast to wild type and crk36 plants. Conversely, CRK36 overexpression increased resistance to Pst DC3000 and Pst DC3000 (AvrRpm1), decreasing bacterial growth in inoculated leaves. Our results suggest that disease resistance phenotypes may be correlated with a positive role of CRK36 in cell death. Pathogen-induced PCD has been suggested as a mechanism to restrict the growth and spread of pathogens to other uninfected tissues, as observed in Pst DC3000 (AvrRpm1)- and Pst DC3000 (AvrRpt2)-infiltrated leaves. In contrast, necrotrophic pathogens assimilate nutrients from dead tissues and thus profit from host cell death (Govrin and Levine, 2000; Mayer et al., 2011). Enhanced cell death in CRK36OE plants would provide favorable conditions for the proliferation of $A$. brassicicola and E. carotovora. Other types of cell death, e.g., cell death triggered by fungal toxin FB1 and during senescence, were also positively affected by CRK36. These results suggest that CRK36 plays a positive role in PCD processes.

\section{ROS Production and Stomatal Immunity}

ROS are generated during oxidizing metabolic processes in peroxisomes, mitochondria, and chloroplasts, and have long been regarded as toxic by-products that cause photooxidative damage to DNA, proteins, and lipids. However, the identification of enzyme-mediated ROS production and detoxification mechanisms has revealed the regulatory roles of ROS in cell signaling and homeostasis (Robson and Vanlerberghe, 2002; Mittler et al., 2004; Moons, 2005; Torres et al., 2006; Bhattacharjee, 2012). ROS, acting as signaling molecules, regulate various biological processes, including cell growth, development, and abiotic and biotic stress responses (Gechev et al., 2006; Pitzschke et al., 2006; Miller et al., 2010). Most notably, ROS has been implicated in plant immunity (Torres et al., 2002; Pogány et al., 2009; Mersmann et al., 2010; Yoshioka et al., 2011; Kadota et al., 2014, 2015; Li et al., 2014). ROS production, the so-called oxidative burst, is one of the earliest responses triggered during plant-pathogen interactions, and is characterized as apoplastic and biphasic. The first phase of ROS production is a rapid and transient response that occurs within minutes of PAMP recognition during PTI (Chinchilla et al., 2007; Gimenez-Ibanez et al., 2009; Daudi et al., 2012; Liu et al., 2013; Li et al., 2014; Macho and Zipfel, 2014). The second phase of ROS production is slower but stronger, and is usually associated with the establishment of HR cell death during ETI (Torres, 2010; Tsuda and Katagiri, 2010; Yoshioka et al., 2011; Caplan et al., 2015). Plasma membrane-localized NADPH oxidases, which belong to the Respiratory Burst Oxidase Homolog ( $\mathrm{RBOH})$ family, are responsible for apoplastic oxidative burst during both PTI and ETI (Torres et al., 2005; Tsuda and Katagiri, 2010; Kadota et al., 2015). Functional analysis of rboh mutants has demonstrated that RbohD is required for ROS production in response to PAMPs and avirulent pathogens (Kadota et al., 2015; Morales et al., 2016). RbohF may also partly contribute to pathogen-induced ROS production, since rbohD rbohF double mutants potentiated defense phenotypes, as compared to individual mutants (Yun et al., 2011; Chaouch et al., 2012; Morales et al., 2016). It has been shown that stomatal defense is central for PTI and that it depends on RbohD-induced ROS production (Kadota et al., 2014, 2015; Li et al., 2014; Arnaud and Hwang, 2015). In this study, ROS accumulated during AvrRpm1and AvrRpt2-induced ETI and flg22-induced PTI responses, and in both responses, ROS production was further increased by CRK36 overexpression. In CRK36OE plants, flg22-induced stomatal closure and resistance to Pst DC3000 were enhanced, both of which required RbohD/F. Conversely, ROS burst and stomatal immune responses were decreased in crk36 plants as compared to wild type plants. These results suggest that CRK36 
plays a positive role in Rboh-mediated ROS production and stomatal defense during innate immune responses.

Yeh et al. (2015) recently reported that CRK4, CRK6, and CRK36 regulate PTI and physically interact with FLS2 in protoplasts. Whereas the binding of FLS2 with BAK1 depends on PAMP flagellin or flg22 (Chinchilla et al., 2007; Lu et al., 2010; Schulze et al., 2010), FLS2 interacted with CRK36 as well as CRK4 and CRK6 in an flg22-independent manner (Yeh et al., 2015). The association of CRK36 with FLS2 was further confirmed in our study. We additionally showed that CRK36 interacts with BIK1. As BIK1 associates with PRRs (Lu et al., 2010; Zhang et al., 2010; Couto et al., 2016), CRK36 may be a component of PRR complexes. In the present study, CRK36 was isolated as an A. brassicicola-responsive gene and positively regulated fungal resistance. Fungal PAMPs, including chitin, have been identified and chitin elicitor receptor kinase 1 (CERK1) functions as a chitin-responsive PRR (Nürnberger et al., 2004). BIK1 has been shown to interact with CERK1 (Zhang et al., 2010), suggesting that CRK36 may be also involved in fungal PTI. However, BAK1 does not interact with CERK1 but is engaged in the ERECTA LRR-RLK complex during necrotrophic fungal resistance (Jordá et al., 2016). It would be important to investigate whether fungal PAMPs form PRR complexes composed of known PTI components and induce common PTI signaling.

While ROS are considered important signaling molecules, it is not known how ROS are perceived in the apoplast and how they are relayed to signaling events of PTI and ETI. Recently, Kimura et al. (2017) have reviewed the role of ROS in RLK signaling and ROS-RLK crosstalk in the context of stomatal immunity. They suggest a potential role for CRKs in the regulation of ROS production, although the exact mechanism is unclear. CRKs have DUF26 domains with conserved Cys $\left(\mathrm{C}-\mathrm{X}_{8}-\mathrm{C}-\mathrm{X}_{2}-\mathrm{C}\right)$ that have been suggested as targets of redox modification, placing them as potential "ROS receptors" or as a part of the ROS sensing system (Wrzaczek et al., 2010, 2013; Bourdais et al., 2015). It was recently shown that the extracellular Cys residues are required for CRK28induced cell death in $N$. benthamiana (Yadeta et al., 2017). In our work, CRK36 ${ }^{\mathrm{C} 12345 A} \mathrm{OE}$ and $C R K 36^{\mathrm{C} 6789 A} \mathrm{OE}$ plants with Cys-toAla mutations were impaired in both ETI and PTI responses. Intriguingly, flg22-triggered BIK1 phosphorylation was largely abolished in $C R K 36^{\mathrm{C} 12345 \mathrm{~A}} \mathrm{OE}$ and $C R K 36^{\mathrm{C} 6789 \mathrm{~A}} \mathrm{OE}$ protoplasts, although Cys mutant forms CRK36 ${ }^{\mathrm{C} 12345 \mathrm{~A}}$ and CRK36 ${ }^{\mathrm{C} 6789 \mathrm{~A}}$ were still able to associate with BIK1. We demonstrate that the conserved Cys residues in the DUF26 domains are essential for CRK36 functions.

\section{REFERENCES}

Acharya, B. R., Raina, S., Maqbool, S. B., Jagadeeswaran, G., Mosher, S. L., Appel, H. M., et al. (2007). Overexpression of CRK13, an Arabidopsis cysteine-rich receptor-like kinase, results in enhanced resistance to Pseudomonas syringae. Plant J. 50, 488-499. doi: 10.1111/j.1365-313X.2007. 03064.x

Arnaud, D., and Hwang, I. (2015). A sophisticated network of signaling pathways regulates stomatal defenses to bacterial pathogens. Mol. Plant. 8, 566-581. doi: 10.1016/j.molp.2014.10.012

\section{A Proposed Model for CRK36 Functions in Immunity}

We propose a model in which CRK36 functions as an ROS receptor and participates in a positive activation loop of CRK36, BIK1, NADPH oxidase, and ROS (Figure 7C). CRK36 is activated by sensing ROS through redox modification of Cys residues in the DUF26 domains. This triggers the phosphorylation and activation of BIK1. The activated BIK1 then phosphorylates RbohD, boosting ROS burst and stomatal immunity. In our model, CRK36 activation requires the initial ROS burst triggered by BIK1, which is activated upon flg22 binding to the FLS2-BAK1 complex. It will be important to examine whether and how the FLS2-BAK1 and FLS2-CRK36 complexes are connected to regulate PTI responses. Additional studies on the role of DUF26 domains in redox regulation would enhance our understanding of the structure and function of CRKs.

\section{AUTHOR CONTRIBUTIONS}

DL and OP designed the research. DL, YK, SK, and CR performed the research. DL and OP analyzed the data and wrote the article.

\section{FUNDING}

This work was supported by a Korea University grant, the Next-Generation BioGreen 21 Programs (SSAC, PJ011209; Plant Molecular Breeding Center, PJ011210) through the Rural Development Administration, and a National Research Foundation of Korea (NRF) grant funded by the Korean government (2017R1A2B4009991).

\section{ACKNOWLEDGMENTS}

We thank June M. Kwak for $r b o h D / F$ and Libo Shan for bik1 seeds. We also thank Hye-Jung Lee for critical reading of the manuscript.

\section{SUPPLEMENTARY MATERIAL}

The Supplementary Material for this article can be found online at: https://www.frontiersin.org/articles/10.3389/fpls.2017. 01856/full\#supplementary-material

Bhattacharjee, S. (2012). The language of reactive oxygen species signaling in plants. J. Bot. 2012, 1-22. doi: 10.1155/2012/985298

Boller, T., and Felix, G. (2009). A renaissance of elicitors: perception of microbe-associated molecular patterns and danger signals by pattern-recognition receptors. Annu. Rev. Plant Biol. 60, 379-406. doi: 10.1146/annurev.arplant.57.032905.105346

Bourdais, G., Burdiak, P., Gauthier, A., Nitsch, L., Salojärvi, J., Rayapuram, C., et al. (2015). Large-scale phenomics identifies primary and fine-tuning roles for CRKs in responses related to oxidative stress. PLoS Genet. 11:e1005373. doi: 10.1371/journal.pgen.1005373 
Bowling, S. A., Clarke, J. D., Liu, Y., Klessig, D. F., and Dong, X. (1997). The cpr5mutant of Arabidopsis expresses both NPR1-dependent and NPR1independentresistance. Plant Cell 9, 1574-1584.

Burdiak, P., Rusaczonek, A., Witon, D., Głów, D., and Karpinski, S. (2015). Cysteine-rich receptor-like kinase CRK5 as a regulator of growth, development, and ultraviolet radiation responses in Arabidopsis thaliana. J. Exp. Bot. 66, 3325-3337. doi: 10.1093/jxb/erv143

Caplan, J. L., Kumar, A. S., Park, E., Padmanabhan, M. S., Hoban, K., Modla, S., et al. (2015). Chloroplast stromules function during innate immunity. Dev. Cell 34, 45-57. doi: 10.1016/j.devcel.2015.05.011

Chaouch, S., Queval, G., and Noctor, G. (2012). AtRbohF is a crucial modulator of defence-associated metabolism and a key actor in the interplay between intracellular oxidative stress and pathogenesis responses in Arabidopsis. Plant J. 69, 613-627. doi: 10.1111/j.1365-313X.2011.04816.x

Chen, K., Du, L., and Chen, Z. (2003). Sensitization of defense responses and activation of programmed cell death by a pathogen-induced receptor-like protein kinase in Arabidopsis. Plant Mol. Biol. 53, 61-74. doi: 10.1023/B:PLAN.0000009265.72567.58

Chen, K., Fan, B., Du, L., and Chen, Z. (2004). Activation of hypersensitive cell death by pathogen-induced receptor-like protein kinases from Arabidopsis. Plant Mol. Biol. 56, 271-283. doi: 10.1007/s11103-004-3381-2

Chen, Z. (2001). A superfamily of proteins with novel cysteine-rich repeats. Plant Physiol. 126, 473-476. doi: 10.1104/pp.126.2.473

Chinchilla, D., Bauer, Z., Regenass, M., Boller, T., and Felix, G. (2006). The Arabidopsis receptor kinase FLS2 binds flg22 and determines the specificity of flagellin perception. Plant Cell 18, 465-476. doi: 10.1105/tpc.105.036574

Chinchilla, D., Zipfel, C., Robatzek, S., Kemmerling, B., Nürnberger, T., Jones, J. D., et al. (2007). A flagellin-induced complex of the receptor FLS2 and BAK1 initiates plant defence. Nature 448, 497. doi: 10.1038/nature05999

Clay, N. K., Adio, A. M., Denoux, C., Jander, G., and Ausubel, F. M. (2009). Glucosinolate metabolites required for an Arabidopsis innate immune response. Science 323, 95-101. doi: 10.1126/science.1164627

Clough, S. J., and Bent, A. F. (1998). Floral dip: a simplified method for Agrobacterium-mediated transformation of Arabidopsis thaliana. Plant J. 16, 735-743. doi: 10.1046/j.1365-313x.1998.00343.x

Coll, N. S., Epple, P., and Dangl, J. L. (2011). Programmed cell death in the plant immune system. Cell Death Differ. 18, 1247-1256. doi: 10.1038/cdd.2011.37

Couto, D., Niebergall, R., Liang, X., Bücherl, C. A., Sklenar, J., Macho, A. P., et al. (2016). The Arabidopsis protein phosphatase PP2C38 negatively regulates the central immune kinase BIK1. PLoS Pathog. 12:e1005811. doi: 10.1371/journal.ppat.1005811

Daudi, A., Cheng, Z., O'Brien, J. A., Mammarella, N., Khan, S., Ausubel, F. M., et al. (2012). The apoplastic oxidative burst peroxidase in Arabidopsis is a major component of pattern-triggered immunity. Plant Cell 24, 275-287. doi: 10.1105/tpc.111.093039

Diévart, A., and Clark, S. E. (2004). LRR-containing receptors regulating plant development and defense. Development 131, 251-261. doi: 10.1242/dev.00998

Dixon, D. P., Davis, B. G., and Edwards, R. (2002). Functional divergence in the glutathione transferase superfamily in plants identification of two classes with putative functions in redox homeostasis in Arabidopsis thaliana. J. Biol. Chem. 277, 30859-30869. doi: 10.1074/jbc.M202919200

$\mathrm{Du}, \mathrm{L}$., and Chen, Z. (2000). Identification of genes encoding receptorlike protein kinases as possible targets of pathogen-and salicylic acidinduced WRKY DNA-binding proteins in Arabidopsis. Plant J. 24, 837-847. doi: 10.1046/j.1365-313x.2000.00923.x

Ederli, L., Madeo, L., Calderini, O., Gehring, C., Moretti, C., Buonaurio, R., et al. (2011). The Arabidopsis thaliana cysteine-rich receptor-like kinase CRK20 modulates host responses to Pseudomonas syringae pv. tomato DC3000 infection. Plant Physiol. 168, 1784-1794. doi: 10.1016/j.jplph.2011.05.018

Gechev, T. S., Van Breusegem, F., Stone, J. M., Denev, I., and Laloi, C. (2006). Reactive oxygen species as signals that modulate plant stress responses and programmed cell death. Bioessays 28, 1091-1101. doi: 10.1002/bies.20493

Gimenez-Ibanez, S., Ntoukakis, V., and Rathjen, J. P. (2009). The LysM receptor kinase CERK1 mediates bacterial perception in Arabidopsis. Plant Signal. Behav. 4, 539-541. doi: 10.4161/psb.4.6.8697

Govrin, E. M., and Levine, A. (2000). The hypersensitive response facilitates plant infection by the necrotrophic pathogen Botrytis cinerea. Curr. Biol. 10, 751-757.doi: 10.1016/S0960-9822(00)00560-1
Heese, A., Hann, D. R., Gimenez-Ibanez, S., Jones, A. M., He, K., Li, J., et al. (2007). The receptor-like kinase SERK3/BAK1 is a central regulator of innate immunity in plants. Proc. Natl. Acad. Sci. U.S.A 104, 12217-12222. doi: 10.1073/pnas.0705306104

Huh, S. M., Noh, E. K., Kim, H. G., Jeon, B. W., Bae, K., Hu, H. C., et al. (2010). Arabidopsis annexins AnnAt1 and AnnAt4 interact with each other and regulate drought and salt stress responses. Plant Cell Physiol. 51, 1499-1514. doi: $10.1093 /$ pcp/pcq111

Jefferson, R. A., Kavanagh, T. A., and Bevan, M. W. (1987). GUS fusions: betaglucuronidase as a sensitive and versatile gene fusion marker in higher plants. EMBO J. 6, 3901-3907.

Jordá, L., Sopeña-Torres, S., Escudero, V., Nuñez-Corcuera, B., Delgado-Cerezo, M., Torii, K. U., et al. (2016). ERECTA and BAK1 receptor like kinases interact to regulate immune responses in Arabidopsis. Front. Plant Sci. 7:897. doi: $10.3389 /$ fpls.2016.00897

Kadota, Y., Shirasu, K., and Zipfel, C. (2015). Regulation of the NADPH oxidase RBOHD during plant immunity. Plant Cell Physiol. 56, 1472-1480. doi: $10.1093 / \mathrm{pcp} / \mathrm{pcv} 063$

Kadota, Y., Sklenar, J., Derbyshire, P., Stransfeld, L., Asai, S., Ntoukakis, V., et al. (2014). Direct regulation of the NADPH oxidase RBOHD by the PRR-associated kinase BIK1 during plant immunity. Mol. Cell 54, 43-55. doi: 10.1016/j.molcel.2014.02.021

Kim, H. G., Kwon, S. J., Jang, Y. J., Nam, M. H., Chung, J. H., Na, Y. C., et al. (2013). GDSL LIPASE1 modulates plant immunity through feedback regulation of ethylene signaling. Plant Physiol. 163, 1776-1791. doi: 10.1104/pp.113.225649

Kimura, S., Waszczak, C., Hunter, K., and Wrzaczek, M. (2017). Bound by fate: reactive oxygen species in receptor-like kinase signaling. Plant Cell 29, 638-654. doi: $10.1105 /$ tpc. 16.00947

Koller, T., and Bent, A. F. (2014). FLS2-BAK1 extracellular domain interaction sites required for defense signaling activation. PLOS ONE 9:e111185. doi: 10.1371/journal.pone.0111185

Konert, G., Rahikainen, M., Trotta, A., Durian, G., Salojärvi, J., Khorobrykh, S., et al. (2015). Subunits $B^{\prime} \gamma$ and $B^{\prime} \zeta$ of protein phosphatase $2 A$ regulate photo-oxidative stress responses and growth in Arabidopsis thaliana. Plant Cell Environ. 38, 2641-2651. doi: 10.1111/pce.12575

Kwak, J. M., Mori, I. C., Pei, Z. M., Leonhardt, N., Torres, M. A., Dangl, J. L., et al. (2003). NADPH oxidase AtrbohD and AtrbohF genes function in ROS-dependent ABA signaling in Arabidopsis. EMBO J. 22, 2623-2633. doi: $10.1093 / \mathrm{emboj} / \mathrm{cdg} 277$

Kwon, S. I., Cho, H. J., Bae, K., Jung, J. H., Jin, H. C., and Park, O. K. (2009). Role of an Arabidopsis RabGTPase RabG3b in pathogen response and leaf senescence. J. Plant Biol. 52, 79-87. doi: 10.1007/s12374-009-9011-4

Kwon, S. I., Cho, H. J., Kim, S. R., and Park, O. K. (2013). The RabGTPase RabG3b positively regulates autophagy and immunity-associated hypersensitive cell death in Arabidopsis. Plant Physiol. 161, 1722-1736. doi: 10.1104/pp.112.208108

Li, L., Li, M., Yu, L., Zhou, Z., Liang, X., Liu, Z., et al. (2014). The FLS2-associated kinase BIK1 directly phosphorylates the NADPH oxidase RbohD to control plant immunity. Cell Host Microbe 15, 329-338. doi: 10.1016/j.chom.2014.02.009

Lim, P. O., Kim, H. J., and Nam, H. G. (2007). Leaf senescence. Annu. Rev. Plant Biol. 58, 115-136. doi: 10.1146/annurev.arplant.57.032905.105316

Lin, W., Li, B., Lu, D., Chen, S., Zhu, N., He, P., et al. (2014). Tyrosine phosphorylation of protein kinase complex BAK1/BIK1 mediates Arabidopsis innate immunity. Proc. Natl. Acad. Sci. U.S.A. 111, 3632-3637. doi: 10.1073/pnas.1318817111

Liu, Z., Wu, Y., Yang, F., Zhang, Y., Chen, S., Xie, Q., et al. (2013). BIK1 interacts with PEPRs to mediate ethylene-induced immunity. Proc. Natl. Acad. Sci. U.S.A. 110, 6205-6210. doi: 10.1073/pnas.12155 43110

Lu, D., Wu, S., Gao, X., Zhang, Y., Shan, L., and He, P. (2010). A receptorlike cytoplasmic kinase, BIK1, associates with a flagellin receptor complex to initiate plant innate immunity. Proc. Natl. Acad. Sci. U.S.A. 107, 496-501. doi: 10.1073/pnas.0909705107

Macho, A. P., and Zipfel, C. (2014). Plant PRRs and the activation of innate immune signaling. Mol. Cell 54, 263-272. doi: 10.1016/j.molcel.2014.03.028

MacKey, D., Belkhadir, Y., Alonso, J. M., Ecker, J. R., and Dangl, J. L. (2003). Arabidopsis RIN4 is a target of the type III virulence effector 
AvrRpt2 and modulates RPS2-mediated resistance. Cell 112, 379-389. doi: 10.1016/S0092-8674(03)00040-0

Mackey, D., Holt, B. F., Wiig, A., and Dangl, J. L. (2002). RIN4 interacts with Pseudomonas syringae type III effector molecules and is required for RPM1-mediated resistance in Arabidopsis. Cell 108, 743-754. doi: 10.1016/S0092-8674(02)00661-X

Mayer, W. E., Schuster, L. N., Bartelmes, G., Dieterich, C., and Sommer, R. J. (2011). Horizontal gene transfer of microbial cellulases into nematode genomes is associated with functional assimilation and gene turnover. BMC Evol. Biol. 11:13. doi: 10.1186/1471-2148-11-13

Melotto, M., Underwood, W., Koczan, J., Nomura, K., and He, S. Y. (2006). Plant stomata function in innate immunity against bacterial invasion. Cell 126, 969-980. doi: 10.1016/j.cell.2006.06.054

Mersmann, S., Bourdais, G., Rietz, S., and Robatzek, S. (2010). Ethylene signaling regulates accumulation of the FLS2 receptor and is required for the oxidative burst contributing to plant immunity. Plant Physiol. 154, 391-400. doi: $10.1104 /$ pp. 110.154567

Miller, G., Suzuki, N., Ciftci-Yilmaz, S., and Mittler, R. (2010). Reactive oxygen species homeostasis and signalling during drought and salinity stresses. Plant Cell Environ. 33, 453-467. doi: 10.1111/j.1365-3040.2009.02041.x

Mittler, R., Vanderauwera, S., Gollery, M., and Van Breusegem, F. (2004). Reactive oxygen gene network of plants. Trends Plant Sci. 9, 490-498. doi: 10.1016/j.tplants.2004.08.009

Monaghan, J., and Zipfel, C. (2012). Plant pattern recognition receptor complexes at the plasma membrane. Curr. Opin. Plant Biol. 15, 349-357. doi: 10.1016/j.pbi.2012.05.006

Moons, A. (2005). Regulatory and functional interactions of plant growth regulators and plant glutathione S-transferases (GSTs). Vitam. Horm. 7, 155-202. doi: 10.1016/S0083-6729(05)72005-7

Morales, J., Kadota, Y., Zipfel, C., Molina, A., and Torres, M. A. (2016). The Arabidopsis NADPH oxidases RbohD and RbohF display differential expression patterns and contributions during plant immunity. J. Exp. Bot. 67, 1663-1676. doi: 10.1093/jxb/erv558

Nicaise, V., Roux, M., and Zipfel, C. (2009). Recent advances in PAMP-triggered immunity against bacteria: pattern recognition receptors watch over and raise the alarm. Plant Physiol. 150, 1638-1647. doi: 10.1104/pp.109.139709

Nürnberger, T., Brunner, F., Kemmerling, B., and Piater, L. (2004). Innate immunity in plants and animals: striking similarities and obvious differences. Immunol. Rev. 198, 249-266. doi: 10.1111/j.0105-2896.2004.0119.x

Obayashi, T., Kinoshita, K., Nakai, K., Shibaoka, M., Hayashi, S., Saeki, D., et al. (2007). ATTED-II: a database of co-expressed genes and cis elements for identifying co-regulated gene groups in Arabidopsis. Nucleic Acids Res. 35, D863-D869. doi: 10.1093/nar/gkl783

Oh, I. S., Park, A. R., Bae, M. S., Kwon, S. J., Kim, Y. S., Lee, J. E., et al. (2005). Secretome analysis reveals an Arabidopsis lipase involved in defense against Alternaria brassicicola. Plant Cell 17, 2832-2847. doi: 10.1105/tpc.105. 034819

Osakabe, Y., Yamaguchi-Shinozaki, K., Shinozaki, K., and Tran, L. S. (2013). Sensing the environment: key roles of membrane-localized kinases in plant perception and response to abiotic stress. J. Exp. Bot. 64, 445-458. doi: $10.1093 / \mathrm{jxb} / \mathrm{ers} 354$

Pitzschke, A., Forzani, C., and Hirt, H. (2006). Reactive oxygen species signaling in plants. Antioxid. Redox Signal. 8, 1757-1764. doi: 10.1089/ars.2006.8.1757

Pogány, M., von Rad, U., Grün, S., Dong,ó, A., Pintye, A., Simoneau, P., et al. (2009). Dual roles of reactive oxygen species and NADPH oxidase RBOHD in an Arabidopsis-Alternaria pathosystem. Plant Physiol. 151, 1459-1475. doi: 10.1104/pp.109.141994

Quirino, B. F., Noh, Y. S., Himelblau, E., and Amasino, R. M. (2000). Molecular aspects of leaf senescence. Trends Plant Sci. 5, 278-282. doi: 10.1016/S1360-1385(00)01655-1

Ramegowda, V., and Senthil-Kumar, M. (2015). The interactive effects of simultaneous biotic and abiotic stresses on plants: mechanistic understanding from drought and pathogen combination. J. Plant Physiol. 176, 47-54. doi: 10.1016/j.jplph.2014.11.008

Robatzek, S., Chinchilla, D., and Boller, T. (2006). Ligand-induced endocytosis of the pattern recognition receptor FLS2 in Arabidopsis. Genes Dev. 20, 537-542. doi: $10.1101 /$ gad.366506
Robson, C. A., and Vanlerberghe, G. C. (2002). Transgenic plant cells lacking mitochondrial alternative oxidase have increased susceptibility to mitochondria-dependent and -independent pathways of programmed cell death. Plant Physiol. 129, 1908-1920. doi: 10.1104/pp.004853

Schmittgen, T. D., and Livak, K. J. (2008). Aanlyzing real-time PCR data by the comparative $\mathrm{C}(\mathrm{T})$ method. Nat. Protoc. 3, 1108-1108. doi: 10.1038/nprot.2008.73

Schulze, B., Mentzel, T., Jehle, A. K., Mueller, K., Beeler, S., Boller, T., et al. (2010). Rapid heteromerization and phosphorylation of ligand-activated plant transmembrane receptors and their associated kinase BAK1. J. Biol. Chem. 285, 9444-9451. doi: 10.1074/jbc.M109.096842

Shan, L., He, P., Li, J., Heese, A., Peck, S. C., Nürnberger, T., et al. (2008). Bacterial effectors target the common signaling partner BAK1 to disrupt multiple MAMP receptor-signaling complexes and impede plant immunity. Cell Host Microbe 4, 17-27. doi: 10.1016/j.chom.2008.05.017

Shao, F., Golstein, C., Ade, J., Stoutemyer, M., Dixon, J. E., and Innes, R. W. (2003). Cleavage of Arabidopsis PBS1 by a bacterial type III effector. Science 301, 1230-1233. doi: 10.1126/science.1085671

Shiu, S. H., and Bleecker, A. B. (2001). Receptor-like kinases from Arabidopsis form a monophyletic gene family related to animal receptor kinases. Proc. Natl. Acad. Sci. U.S.A. 98, 10763-10768. doi: 10.1073/pnas. 181141598

Smith, J. M., and Heese, A. (2014). Rapid bioassay to measure early reactive oxygen species production in Arabidopsis leave tissue in response to living Pseudomonas syringae. Plant Methods 10:6. doi: 10.1186/1746-4811-10-6

Tanaka, H., Osakabe, Y., Katsura, S., Mizuno, S., Maruyama, K., Kusakabe, K., et al. (2012). Abiotic stress-inducible receptor-like kinases negatively control ABA signaling in Arabidopsis. Plant J. 70, 599-613. doi: 10.1111/j.1365-313X.2012.04901.x

Tang, J., Liu, J., Zhou, C., Ostanin, D., Grisham, M. B., Neil Granger, D., et al. (1998). Role of NADPH oxidase in the brain injury of intracerebral hemorrhage. J. Neurochem. 94, 1342-1350.

Torres, M. A. (2010). ROS in biotic interactions. Physiol. Plant. 138, 414-429. doi: 10.1111/j.1399-3054.2009.01326.x

Torres, M. A., Dangl, J. L., and Jones, J. D. (2002). Arabidopsis gp9lphox homologues AtrbohD and AtrbohF are required for accumulation of reactive oxygen intermediates in the plant defense response. Proc. Natl. Acad. Sci. U.S.A. 99, 517-522. doi: 10.1073/pnas.012452499

Torres, M. A., Jones, J. D., and Dangl, J. L. (2005). Pathogen-induced, NADPH oxidase-derived reactive oxygen intermediates suppress spread of cell death in Arabidopsis thaliana. Nat. Genet. 37, 1130-1134. doi: 10.1038/ng1639

Torres, M. A., Jones, J. D., and Dangl, J. L. (2006). Reactive oxygen species signaling in response to pathogens. Plant Physiol. 141, 373-378. doi: 10.1104/pp.106.079467

Tsuda, K., and Katagiri, F. (2010). Comparing signaling mechanisms engaged in pattern-triggered and effector-triggered immunity. Curr. Opin. Plant Biol. 13, 459-465. doi: 10.1016/j.pbi.2010.04.006

Veronese, P., Nakagami, H., Bluhm, B., Abuqamar, S., Chen, X., Salmeron, J., et al. (2006). The membrane-anchored BOTRYTIS-INDUCED KINASE1 plays distinct roles in Arabidopsis resistance to necrotrophic and biotrophic pathogens. Plant Cell 18, 257-273. doi: 10.1105/tpc.105.035576

Walter, M., Chaban, C., Schütze, K., Batistic, O., Weckermann, K., Näke, C., et al. (2004). Visualization of protein interactions in living plant cells using bimolecular fluorescence complementation. Plant J. 40, 428-438. doi: 10.1111/j.1365-313X.2004.02219.x

Wrzaczek, M., Brosché, M., and Kangasjärvi, J. (2013). ROS signaling loopsproduction, perception, regulation. Curr. Opin. Plant Biol. 16, 575-582. doi: 10.1016/j.pbi.2013.07.002

Wrzaczek, M., Brosché, M., Salojärvi, J., Kangasjärvi, S., Idänheimo, N., Mersmann, S., et al. (2010). Transcriptional regulation of the CRK/DUF26 group of receptor-like protein kinases by ozone and plant hormones in Arabidopsis. BMC Plant Biol. 10:95. doi: 10.1186/1471-2229-10-95

Yadeta, K. A., Elmore, J. M., Creer, A. Y., Feng, B., Franco, J. Y., Rufian, J. S., et al. (2017). A cysteine-rich protein kinase associates with a membrane immune complex and the cysteine residues are required for cell death. Plant Physiol. 173, 771-787. doi: 10.1104/pp.16.01404

Yeh, Y. H., Chang, Y. H., Huang, P. Y., Huang, J. B., and Zimmerli, L. (2015). Enhanced Arabidopsis pattern-triggered immunity by 
overexpression of cysteine-rich receptor-like kinases. Front. Plant Sci. 6:322. doi: 10.3389/fpls.2015.00322

Yoo, S. D., Cho, Y. H., and Sheen, J. (2007). Arabidopsis mesophyll protoplasts: a versatile cell system for transient gene expression analysis. Nat. Protoc. 2, 1565-1572. doi: 10.1038/nprot.2007.199

Yoshioka, H., Mase, K., Yoshioka, M., Kobayashi, M., and Asai, S. (2011). Regulatory mechanisms of nitric oxide and reactive oxygen species generation and their role in plant immunity. Nitric Oxide 25, 216-221. doi: 10.1016/j.niox.2010.12.008

Yun, B. W., Feechan, A., Yin, M., Saidi, N. B., Le Bihan, T., Yu, M., et al. (2011). Snitrosylation of NADPH oxidase regulates cell death in plant immunity. Nature 478, 264-268. doi: 10.1038/nature10427

Zeng, W., and He, S. Y. (2010). A prominent role of the flagellin receptor FLAGELLIN-SENSING2 in mediating stomatal response to Pseudomonas syringae pv tomato DC3000 in Arabidopsis. Plant Physiol. 153, 1188-1198. doi: $10.1104 /$ pp.110.157016

Zhang, J., Li, W., Xiang, T., Liu, Z., Laluk, K., Ding, X., et al. (2010). Receptor-like cytoplasmic kinases integrate signaling from multiple plant immune receptors and are targeted by a Pseudomonas syringae effector. Cell Host Microbe 7, 290-301. doi: 10.1016/j.chom.2010.03.007
Zhang, J., Shao, F., Li, Y., Cui, H., Chen, L., Li, H., et al. (2007). A Pseudomonas syringae effector inactivates MAPKs to suppress PAMP-induced immunity in plants. Cell Host Microbe 1, 175-185. doi: 10.1016/j.chom.2007.03.006

Zhang, X., Han, X., Shi, R., Yang, G., Qi, L., Wang, R., et al. (2013). Arabidopsis cysteine-rich receptor-like kinase 45 positively regulates disease resistance to Pseudomonas syringae. Plant Physiol. Biochem. 73, 383-391. doi: 10.1016/j.plaphy.2013.10.024

Zipfel, C. (2014). Plant pattern-recognition receptors. Trends Immunol. 35, 345-351. doi: 10.1016/j.it.2014.05.004

Conflict of Interest Statement: The authors declare that the research was conducted in the absence of any commercial or financial relationships that could be construed as a potential conflict of interest.

Copyright (c) 2017 Lee, Kim, Kwon, Ryu and Park. This is an open-access article distributed under the terms of the Creative Commons Attribution License (CC BY). The use, distribution or reproduction in other forums is permitted, provided the original author(s) or licensor are credited and that the original publication in this journal is cited, in accordance with accepted academic practice. No use, distribution or reproduction is permitted which does not comply with these terms. 